ARTICLE OPEN

\title{
Tissue-resident memory Th17 cells maintain stable fungal commensalism in the oral mucosa
}

\author{
Florian R. Kirchner ${ }^{1,2}$ and Salomé LeibundGut-Landmann (D) ${ }^{1,2}$
}

Keeping a stable equilibrium between the host and commensal microbes to which we are constantly exposed, poses a major challenge for the immune system. The host mechanisms that regulate homeostasis of the microbiota to prevent infection and inflammatory disorders are not fully understood. Here, we provide evidence that $C D 4^{+}$tissue-resident memory $T$ ( $\left.T_{R M}\right)$ cells act as central players in this process. Using a murine model of $C$. albicans commensalism we show that IL-17 producing $\mathrm{CD} 9^{+} \mathrm{CD}_{103}{ }^{+} \mathrm{CD}^{+}$memory $\mathrm{T}$ cells persist in the colonized tissue long-term and independently of circulatory supplies. Consistent with the requirement of Th17 cells for limiting fungal growth, IL-17-producing $\mathrm{T}_{\mathrm{RM}}$ cells in the mucosa were sufficient to maintain prolonged colonization, while circulatory $T$ cells were dispensable. Although $T_{R M}$ cells were first proposed to protect from pathogens causing recurrent acute infections, our results support a central function of $T_{R M}$ cells in the maintenance of commensalism.

Mucosal Immunology (2021) 14:455-467; https://doi.org/10.1038/s41385-020-0327-1

\section{INTRODUCTION}

All epithelial barrier tissues are colonized with complex microbial communities that modulate the balance between health and disease. Maintaining a stable equilibrium with the microbiota represents a major challenge for the immune system. The relevance of fungi as an integral part of the microbiota has recently gained attention. ${ }^{1}$ Active and continuous surveillance of commensal fungi by the immune system is critical for host homeostasis and to prevent disease. ${ }^{2,3}$ In turn, a breach in host defenses e.g. as a consequence of immunosuppression, increases the susceptibility to fungal infections. Overall, fungal infections are a leading cause of disease worldwide and the frequency of reported incidences is on the rise. ${ }^{4}$

Amongst the most abundant human commensal fungi are those of the genus Candida with the most well-known species Candida albicans, colonizing the mucosae of the oral, ${ }^{5,6}$ gastrointestinal ${ }^{7,8}$ or urogenital tract ${ }^{9}$ and skin. ${ }^{10}$ Candida-mediated diseases manifest most frequently as superficial infections that affect the mucosal surfaces, the skin and nails. ${ }^{11}$ More severe forms of disease occur if the fungus reaches the bloodstream and disseminates to visceral organs, where it can cause life-threatening infections that are difficult to diagnose and treat. ${ }^{12}$ Colonization of epithelial barriers with Candida spp. has also been associated with an increased risk for inflammatory pathologies under certain conditions. As such, inflammatory bowel disease, a common inflammatory disorder of the gastrointestinal tract, has been linked to fungal dysbiosis ${ }^{13,14}$ and single nucleotide polymorphisms in genes that are involved in fungal recognition and response have been identified as risk factors for disease. ${ }^{15-17}$ Candida colonization of the gastrointestinal tract has also been linked to allergic disorders at distant sites such as the airways. ${ }^{18,19}$
These examples illustrate the necessity that fungal commensalism is tightly controlled. Our understanding of the immunosurveillance mechanisms that maintain stable colonization and prevent disease in epithelial tissues remains incomplete. The key role of $\mathrm{CD} 4^{+} \mathrm{T}$ cells in protection from $C$. albicans overgrowth has become apparent through the increased frequency of severe and chronic forms of superficial C. albicans infections in individuals with inherited or acquired $T$ cell deficiencies, such as severe combined immunodeficiency or acquired immune deficiency syndrome, respectively. ${ }^{20,21}$ Among $\mathrm{CD}^{+}{ }^{+} \mathrm{T}$ cells, especially those secreting IL-17 are critical for control of $C$. albicans. Individuals with primary immunodeficiencies resulting in defective Th17 immunity, such as STAT3 loss-of-function (LOF) mutations in autosomal-dominant hyper-lgE syndrome, STAT1 gain-of-function mutations, RORC LOF mutations, or CARD9 LOF mutations show a strongly increased risk of developing chronic mucocutaneous candidiasis (CMC). ${ }^{22-30}$ Genetic defects in the IL-17 pathway itself, such as mutations in the IL-17 receptor A (IL-17RA) or IL-17RC subunits, in the signaling component Act1 or in the cytokine IL-17F were also found to underlie CMC. ${ }^{31-33}$

The key role of IL-17-mediated antifungal immunity has been recapitulated in mouse models of oropharyngeal candidiasis (OPC) and epicutaneous candidiasis. Mice lacking IL-17A and IL$17 \mathrm{~F}$ or components of the IL-17 receptor (II17ra ${ }^{-1-}$ and $/ 117 \mathrm{rc}^{-/-}$ mice) display strongly increased fungal loads compared to control mice. ${ }^{34-40}$ The same also applies to mice that lack factors required for the development of IL-17 secreting cells ( orc $^{-1-}$, II23p $19^{-1-}$ mice). ${ }^{34,37,40}$ In addition to T cells, innate lymphoid cells and $\gamma \delta T$ cells have also been implicated in IL-17dependent antifungal immunity in mice, in particular at the onset of infection, ${ }^{34,40-42}$ as most studies so far employed models of acute $C$. albicans infection.

\footnotetext{
${ }^{1}$ Section of Immunology, Vetsuisse Faculty, University of Zürich, Winterthurerstrasse 266a, CH-8057 Zürich, Switzerland and ${ }^{2}$ Institute of Experimental Immunology, University of Zürich, Winterthurerstrasse 190, CH-8057 Zürich, Switzerland

Correspondence: Salomé LeibundGut-Landmann (salome.leibundgut-landmann@uzh.ch)
}

Received: 17 February 2020 Accepted: 6 July 2020

Published online: 27 July 2020 
The species of C. albicans displays a large genetic diversity, ${ }^{43}$ which translates into varying degrees of fitness and virulence of the fungus. Mouse models of $C$. albicans infection facilitated the revelation of functional differences between individual strains in a uniform and C. albicans-naive host background. We and others have shown that this intra-species diversity of $C$. albicans greatly affects the pathogenicity of the fungus and the outcome of its interaction with the host. ${ }^{44-46}$ Highly virulent strains of $C$. albicans, such as the commonly used lab strain SC5314, infect the mucosal tissue of experimentally infected mice only transiently and get rapidly cleared as a result of their capacity to cause damage to epithelial cells. Host cell damage triggers a strong inflammatory response that is characterized by massive cytokine production and influx of neutrophils and monocytes to the site of infection. ${ }^{35,45,47}$ In contrast, C. albicans strains with a low capacity to induce epithelial cell damage induce only a limited degree of inflammation in the tissue and instead persist for a prolonged period of time in the murine oral mucosa. ${ }^{45}$ The lack of a rapid inflammatory host response by these strains is not the consequence of overt immunosuppression by regulatory T cells or IL-10, ${ }^{48}$ but rather due to $C$. albicans-intrinsic differences in the virulence of these strains albeit the underlying genetic basis remains unclear to date.

Although the host response to high- and low-virulent strains of C. albicans displays major qualitative and kinetic differences at the onset of infection, activation of $C$. albicans-specific Th17 immunity is conserved across isolates. ${ }^{45,48}$ Importantly, IL-17 signaling is essential for regulating stable colonization and for preventing fungal overgrowth, irrespective of the strain of $C$. albicans analyzed. ${ }^{45}$

To fathom the mechanisms that ensure continuous immunosurveillance of $C$. albicans during commensalism, we made use of a new experimental model of $C$. albicans persistent colonization in mice using the low-virulent strain 101, which closely mimics the situation in humans. The phenotypic and functional analysis of the dynamics and qualities of the Th17 response in the colonized epithelial tissue revealed a key role of tissue-resident memory $\mathrm{T}$ $\left(T_{R M}\right)$ cells that are maintained independently of the circulating $\mathrm{T}$ cell pool and that are critical for preventing uncontrolled outgrowth of the commensal fungus in the oral mucosa.

\section{RESULTS}

$\mathrm{T}$ cells are required for regulating fungal colonization in the oral mucosa

The experimental model of murine OPC was used extensively to characterize the host response to $C$. albicans in mucosal barrier tissues. However, as in other infection models, the widely used highly virulent strain SC5314 is rapidly cleared from the oral cavity $^{34,37}$ and this precludes monitoring the adaptive immune response against the fungus over time. The observation that the low-virulent C. albicans strain 101 persists for several weeks in the oral mucosa, in some cases up to 1 year, ${ }^{45,48}$ opens new opportunities for assessing the immunosurveillance mechanisms that maintain stable fungal colonization of the host tissue. Although fungal loads remained high in the tongue of strain 101-colonized mice during the entire observation period, we noticed a significant decline between day 7 and 14 post infection (Fig. 1a), which suggested an involvement of the adaptive immune system in the control of the colonization load. Indeed, $\mathrm{Rag}^{-1-}$ and $\mathrm{Tcrbd}^{-1-}$ mice, which lack $\mathrm{T}$ cells, displayed a significantly higher fungal burden on day 7 and day 14 after infection with strain 101, compared to WT mice (Supplementary Fig. S1A-D). Of note, $C D 4^{+} \mathrm{T}$ cells contributed to the maintenance of stable colonization with $C$. albicans in experimentally infected mice also beyond the first 2 weeks of infection. Moreover, adoptive transfer of $C$. albicans-induced polyclonal $\mathrm{CD} 4^{+} \mathrm{T}$ cells or C. albicans-specific TCR-transgenic Hector CD4 ${ }^{+} \mathrm{T}$ cells ${ }^{49}$ into Rag $1^{-1-}$ mice prior to colonization with strain 101 was sufficient to rescue fungal control, with a significant proportion of the transferred cells producing $\mathrm{IL}-17$ and $\mathrm{IL}-22$ in response to $C$. albicans in either case (Supplementary Fig. S1E-H). Finally, we confirmed the relevance of IL-17A and IL-17F for retaining stable fungal loads during colonization over time (Supplementary Fig. S1I). Overall, the situation in C. albicans strain 101-colonized mice is reminiscent of the situation in humans, where a defect in the $T$ cell compartment results in uncontrolled growth of the fungus and in disease. ${ }^{20}$

\section{Colonization with C. albicans strain 101 induces a sustained Th17} cell response

Consistent with the requirement of an intact IL-17 pathway for control of $C$. albicans colonization in humans, the fungus induces a prominent and selective Th17 response during experimental OPC. ${ }^{45,49-51}$ In response to the highly virulent strain SC5314, we found the population of $C$. albicans-specific Th17 cells to contract rapidly after fungal clearance. In contrast, in mice infected with the low-virulent strain 101, fungus-specific Th17 cells were maintained at high frequencies in the cervical lymph nodes at all time points analyzed (Fig. $1 \mathrm{~b}-\mathrm{d}$ ).

We then characterized the cytokine profile of $C$. albicans-specific Th17 cells in the cervical lymph nodes of strain 101-colonized mice in more detail. On day 8 post infection, we observed a prominent population of IL-22-producing $T$ cells, a fraction of which co-produced IL-22 and IL-17 (Fig. 1c, e, f), although IL-22 production was transient and low at later time points (Fig. 1e, f). In contrast, C. albicans-specific $T$ cells expressed only very limited levels of GM-CSF and IFN- $\gamma$ at any time point analyzed (Fig. $1 \mathrm{~g}, \mathrm{~h}$ ). Together, these results show that sustained colonization of the oral mucosa with C. albicans is accompanied with a selective Th17 response that is stably maintained.

\section{$\mathrm{CD}^{+} \mathrm{T}$ cell dynamics in the $C$. albicans-colonized tongue}

Next, we sought to characterize the local $T$ cell response in the tongue of stably colonized mice. For this, we made use of a protocol that was previously established in our lab to isolate tongue $\mathrm{T}$ cells, which are rare in this intractable organ. ${ }^{41,52}$ Starting from 1 week post infection, a small but distinct population of $\mathrm{CD}^{+}{ }^{+} \mathrm{T}$ cells was detected in the tongue of mice infected with C. albicans strain 101 or strain SC5314 (Fig. 2a, b). In line with the rapid clearance of strain SC5314 and the concomitant transient nature of the Th17 response in the cervical lymph nodes (Fig. 1), the CD4 ${ }^{+} \mathrm{T}$ cell population in the tongue also rapidly declined (Fig. 2b). In contrast, during persistent colonization of the oral mucosa with strain 101, high numbers of $\mathrm{CD}^{+} \mathrm{T}$ cells were stably maintained in the tongue throughout the analysis period (Fig. $2 \mathrm{~b}$ ), paralleling the sustained frequency of Th17 cells in the cervical lymph nodes (Fig. 1). To confirm that the difference in tongue $T$ cell dynamics was not the consequence of a putative strain-specific difference that might influence the longevity of the $\mathrm{T}$ cell response, but rather resulted from the differences in persistence of the two strains in the mucosal tissue, we simulated a transient infection with strain 101 by treating colonized mice with the antifungal drug fluconazole from day 8 post infection to eliminate the fungus (Supplementary Fig. S2A). Fungal clearance was accompanied with a rapid decline in T cells in the tongue, indicating that the effect was indeed strain-independent (Fig. 2c).

We also analyzed $\mathrm{CD}^{+} \mathrm{T}$ cells in the tongue of C. albicanscolonized animals. In contrast to $\mathrm{CD}^{+} \mathrm{T}$ cells, this $\mathrm{T}$ cell subset was not enriched in strain 101-compared to strain SC5314infected animals. Except at a very late time point, the frequency of $\mathrm{CD}^{+} \mathrm{T}$ cells was not increased in stably colonized mice in comparison to those that had undergone an acute infection (Supplementary Fig. S2B).

Ex vivo re-stimulation of tongue $\mathrm{CD}^{+}{ }^{+} \mathrm{T}$ cells revealed a pronounced IL-17 production on day 30 and even more 


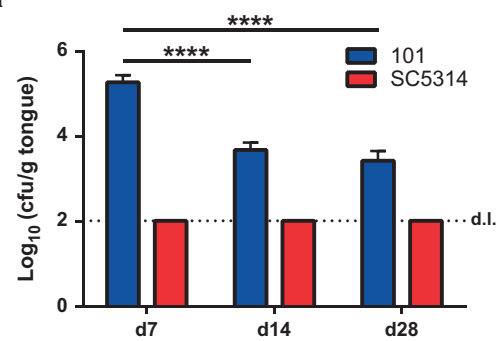

b

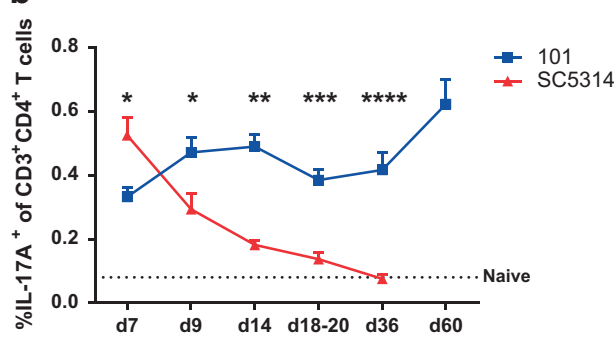

C

Naive

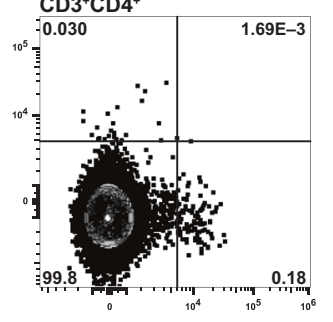

101
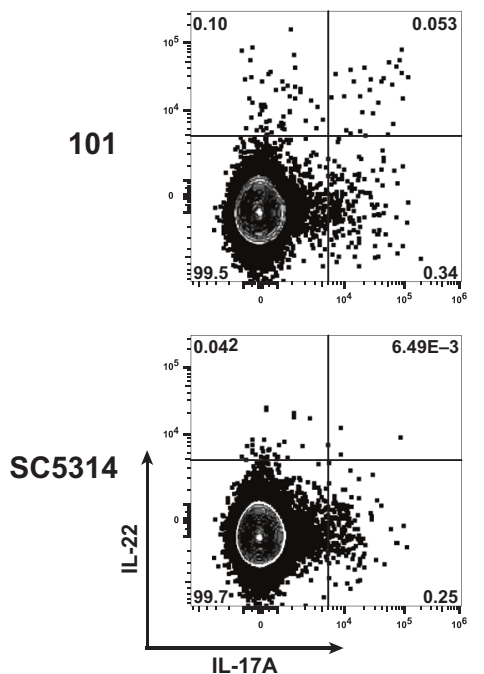
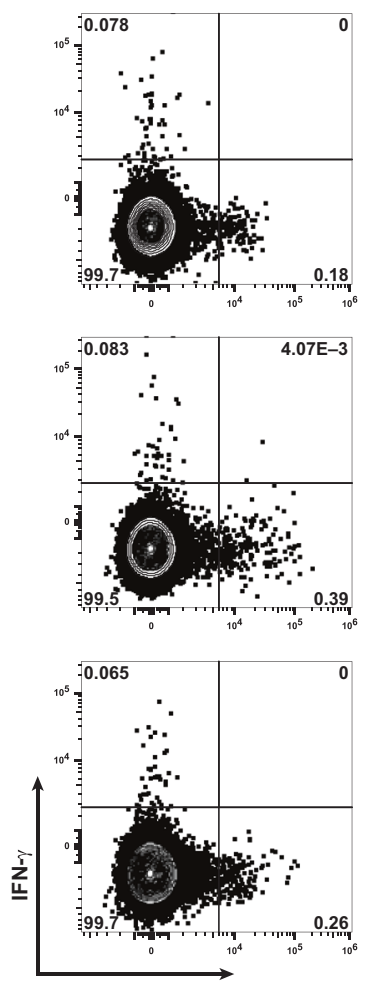

IL-17A

d
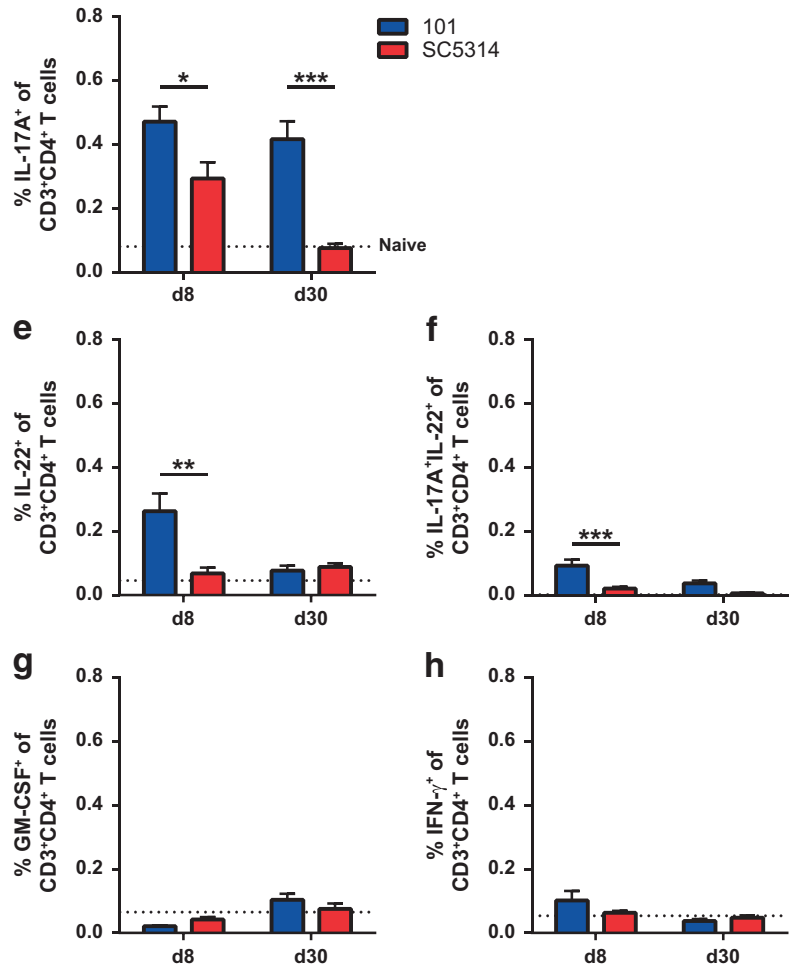

Fig. 1 Th17 cell responses are sustained during stable colonization with $C$. albicans. WT mice were infected sublingually with $C$. albicans strain 101 (blue) or strain SC5314 (red) for the indicated periods of time. a The fungal burden in the tongue was determined by plating tissue homogenates on YPD agar. Data are the mean + SEM of 7-16 individual mice per group pooled from 2-4 independent experiments. The dotted line represents the detection limit (d.I.). b-h Cervical lymph node cells were re-stimulated with C. albicans-pulsed DC ${ }^{1940}$ cells for $5 \mathrm{~h}$ in the presence of Brefeldin A. IL-17A, IL-22, GM-CSF, and IFN- $\gamma$ production was analyzed by intracellular cytokine staining and flow cytometry. Plots show the frequency of cytokine-producing $\mathrm{CD}^{+} \mathrm{CD}^{+}$cells at the indicated time points (b, $\left.\mathbf{d}-\mathbf{h}\right)$ or representative FACS plots for IL-17, IL-22, and IFN- $\gamma$ on day 8 post infection, respectively (c). In (b) data are the mean + SEM of 6-23 mice per group pooled from 2-7 independent experiments. In (d-h), each bar represents the mean + SEM of 8-20 individual mice per group pooled from 2-5 independent experiments. The dotted line represents the mean value determined in naive mice. Statistics were calculated using two-way ANOVA ${ }^{*} p<0.05,{ }^{* *} p<0.01,{ }^{* *} p<$ $0.001,{ }^{* * *} p<0.0001$. See also Supplementary Fig. S1.

pronounced on day 60 post infection with strain 101 (Fig. 2d-f), while in case of strain SC5314-infected animals, no IL-17 production above baseline was detectable at these time points. As in the lymph nodes, tongue $\mathrm{CD}^{+}{ }^{+} \mathrm{T}$ cells did not produce IFN- $\gamma$ in the $C$. albicans-colonized tongue.

IL-23 is a key regulator of the generation of Th17 cells. ${ }^{53}$ We therefore examined the relevance of IL-23 signaling for the Th17 response in the oral mucosa during $C$. albicans colonization. Because IL-23 deficiency impairs fungal control and this would likely have an indirect effect on the Th17 response, we generated mixed bone marrow chimeras using IL-23 receptor-deficient and -sufficient bone marrow to reconstitute WT hosts. This strategy allows uncoupling of the Th17 response from fungal burden. As expected, Th17 cell frequencies within the IL-23R-deficient CD4 ${ }^{+}$ $\mathrm{T}$ cell compartment were strongly reduced in comparison to their
IL-23R-sufficient counterpart in chimeric mice colonized with $C$. albicans strain 101 (Fig. 2g, h). Collectively, these results indicate that stable colonization of the oral mucosa with $C$. albicans results in the accumulation and stable maintenance of Th17 cells in the tongue in an IL-23-dependent manner.

$\mathrm{CD}^{+} \mathrm{T}$ cells in the tongue of $\mathrm{C}$. albicans-colonized mice display a $\mathrm{T}_{\mathrm{RM}}$ phenotype

Next, we interrogated the nature of the $\mathrm{CD}^{+}{ }^{+} \mathrm{T}$ cells in the tongue of $C$. albicans-colonized mice. The population expressed uniformly high levels of $\mathrm{CD}_{4} 4^{+}$and was negative for CD62L (Fig. 3a), a phenotype, corresponding to antigen-experienced effector/memory T cells, while in the cervical lymph nodes of the same animals, which were included in the analysis as a reference, only $~ 15 \%$ of all $\mathrm{CD}^{+} \mathrm{T}$ cells displayed this phenotype, as expected (Fig. 3b). 
a

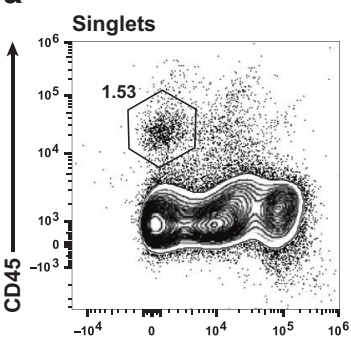

Dead Cell ID $\longrightarrow$
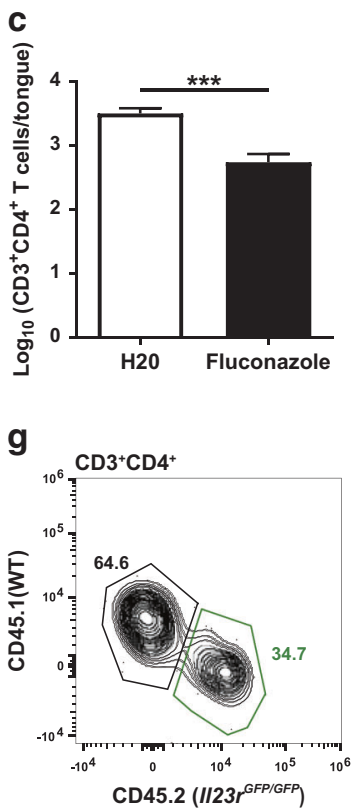

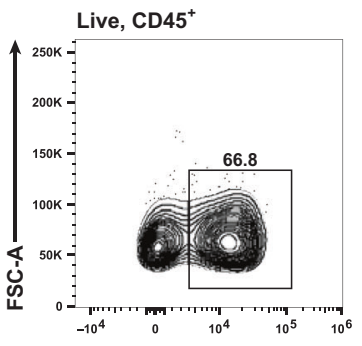

CD3

d

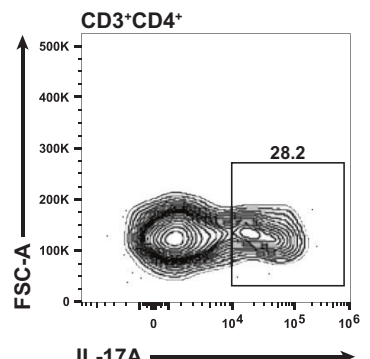

$$
\text { IL-17A } \longrightarrow
$$

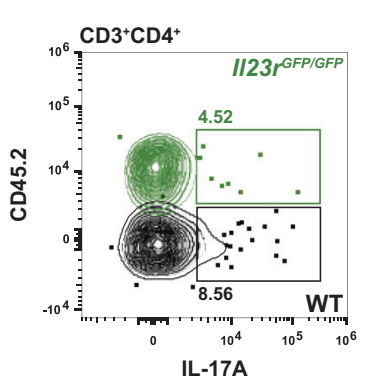

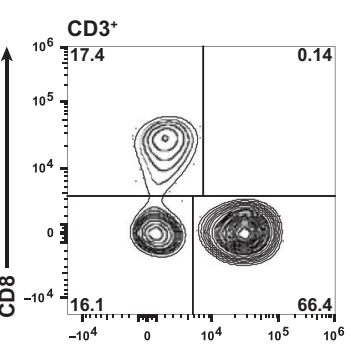

CD4

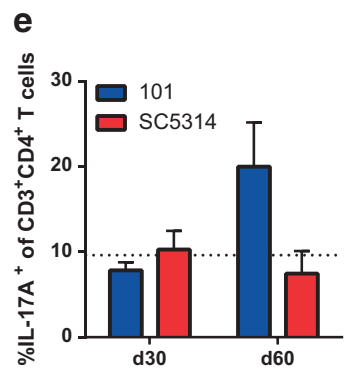

f
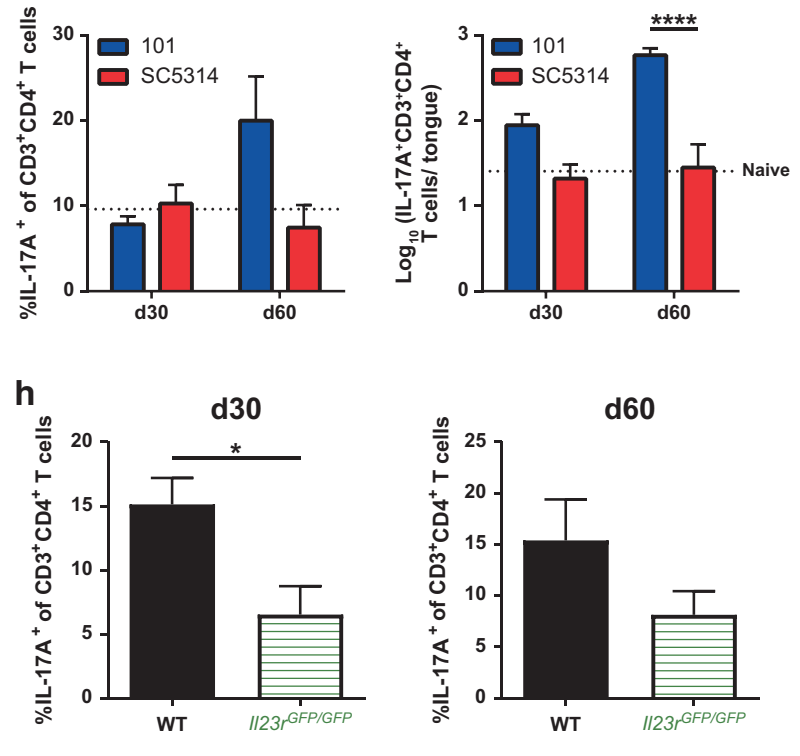

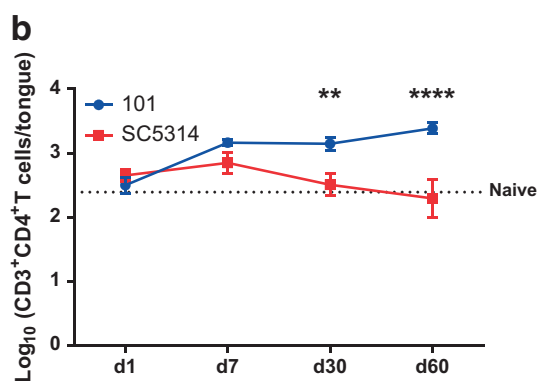

f

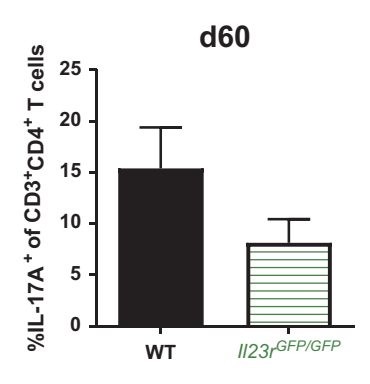

Fig. 2 Th17 cells are maintained in the tongue during stable colonization with $\boldsymbol{C}$. albicans. WT mice were infected sublingually with C. albicans strain 101 (blue) or strain SC5314 (red), respectively, for the indicated periods of time. a Representative FACS plots show the gating strategy for tongue $\mathrm{CD}^{+} \mathrm{CD} 4{ }^{+} \mathrm{T}$ cells. The example shown is from a strain 101-infected mouse on day 60 post infection. b Quantification of tongue $\mathrm{CD}^{+}{ }^{+} \mathrm{T}$ cells at the indicated time points post infection. Each symbol represents the mean $+\mathrm{SEM}$ of 7-13 individual mice per group pooled from 3-4 independent experiments. c Mice infected sublingually with strain 101 were or were not treated with fluconazole starting from day 8 post infection for 14 days. 60 days post infection, $C D 3^{+} \mathrm{CD} 4^{+}$T cells in the tongue were quantified by flow cytometry. Data are the mean + SEM from 7-13 individual mice per group pooled from 3 independent experiments. d-f Tongue cells that were isolated on day 30 or day 60 post infection and re-stimulated ex vivo with PMA and ionomycin for $4 \mathrm{~h}$ in the presence of Brefeldin A. L-17A production by $\mathrm{CD}^{+} \mathrm{CD}^{+} \mathrm{T}$ cells was analyzed by intracellular cytokine staining and flow cytometry. A representative FACS plot is shown in (d); quantification of the frequency (e) and total numbers (f) of IL-17 ${ }^{+} \mathrm{CD} 3^{+} \mathrm{CD} 4^{+} \mathrm{T}$ cells in the tongue. Each bar represents the mean $+\mathrm{SEM}$ of 7-10 individual mice per group pooled from 2-3 independent experiments. $\mathbf{g}, \mathbf{h}$ CD $45.1^{+} \mathrm{CD} 45.2^{+}$WT recipient mice were irradiated and reconstituted with 1:1 mixed bone marrow from CD45.1 $1^{+}$WT and CD45.2 ${ }^{+} / 123 r^{G F P / G F P}$ donor mice. After 8 weeks of reconstitution, chimeric mice were infected sublingually with C. albicans strain 101 for 30 and 60 days. IL-17A production by tongue CD3 ${ }^{+}$CD4 ${ }^{+}$T cells was analyzed by intracellular cytokine staining and flow cytometry after re-stimulation ex vivo with PMA and ionomycin for $4 \mathrm{~h}$ in presence of Brefeldin A. Representative FACS plots of tongue CD4 ${ }^{+}$T cells in either compartment are shown in (g); quantification of the frequency of IL-17 $7^{+} \mathrm{CD}^{+}$ T cells in either compartment are shown in (h). Each bar represents the mean + SEM of 6-7 individual mice pooled from two independent experiments. The dotted lines in $\mathbf{b}, \mathbf{e}$, and $\mathbf{f}$ represent the mean value determined in naive mice. Statistics were calculated using $t$-test (c, $\mathbf{h}$ ) or two-way ANOVA (b, e-f), ${ }^{* *} p<0.01,{ }^{* * *} p<0.001,{ }^{* * * *} p<0.0001$. See also Supplementary Fig. S2.

Furthermore, the majority of the $\mathrm{CD}^{+}$tongue $\mathrm{T}$ cells expressed high levels of CD69 and CD103 (Fig. 3a), two markers characteristic for tissue-resident memory T cells. ${ }^{54}$ CD69 expression supports tissue retention by binding and sequestering the sphingosine-1phosphate receptor 1 (S1pr1), which promotes tissue egress. ${ }^{55}$ $\mathrm{CD} 103$, the aE subunit of the integrin $\mathrm{aE} \beta 7$, binds to $\mathrm{E}$-cadherin expressed on epithelial cells and thereby mediates lymphocyte retention. ${ }^{56}$ Moreover, tongue Th cells in stably colonized mice expressed high levels of CD11a, and to some extent also CD49a, consistent with a $\mathrm{T}_{\mathrm{RM}}$ phenotype (Fig. 3C). ${ }^{54}$ The frequency of $\mathrm{CD}_{103}{ }^{\text {hi }} \mathrm{T}_{\mathrm{RM}}$ cells remained high throughout the analysis period (Fig. 3d). In contrast, in mice that were only transiently exposed to C. albicans, $\mathrm{CD} 103^{\text {hi }} \mathrm{T}_{\mathrm{RM}}$ cells made up only a minor part of the already rare $\mathrm{CD}^{+}$tongue $\mathrm{T}$ cells (Fig. $3 \mathrm{~d}$ ).
In contrast to the situation in the tongue, $\mathrm{CD}^{+} 9^{+} \mathrm{CD} 103^{+} \mathrm{T}_{\mathrm{RM}}$ cells were hardly detectable in the cervical lymph nodes of $C$. albicans strain 101-infected mice. Only a minute proportion of the $\mathrm{CD} 44^{+} \mathrm{CD}_{2} \mathrm{~L}^{-} \mathrm{CD} 4^{+} \mathrm{T}$ cells expressed these markers, irrespective of the fungal strain and the time point of analysis (Fig. 3b, e). The memory $T$ cell subset that was most prominently increased in the cervical lymph nodes of stably colonized mice displayed a $\mathrm{CD} 127^{+} \mathrm{CD}_{4}{ }^{+} \mathrm{CD} 62 \mathrm{~L}^{-}$phenotype characteristic of effector memory $\mathrm{T}$ cells, while $\mathrm{CD} 127^{+} \mathrm{CD} 44^{+} \mathrm{CD} 62^{+}$central memory

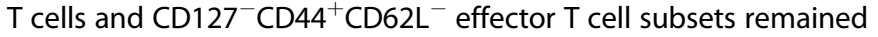
unchanged in comparison to naive mice or mice that had been transiently infected with strain SC5314 (Supplementary Fig. S3). Differences between the groups may appear small. However, it should be noted that antigen-specific T cells make up only a small 


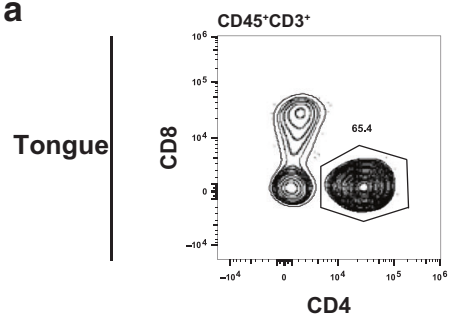

b

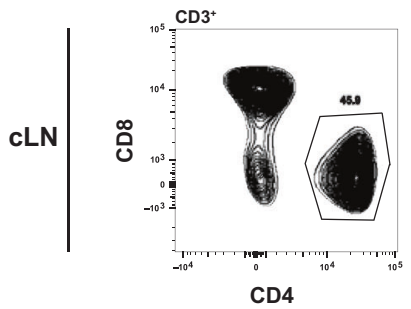

d

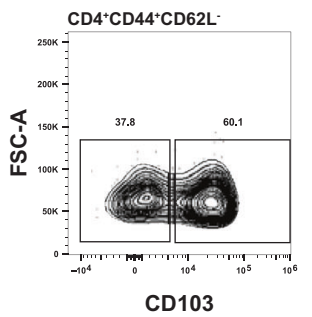

f
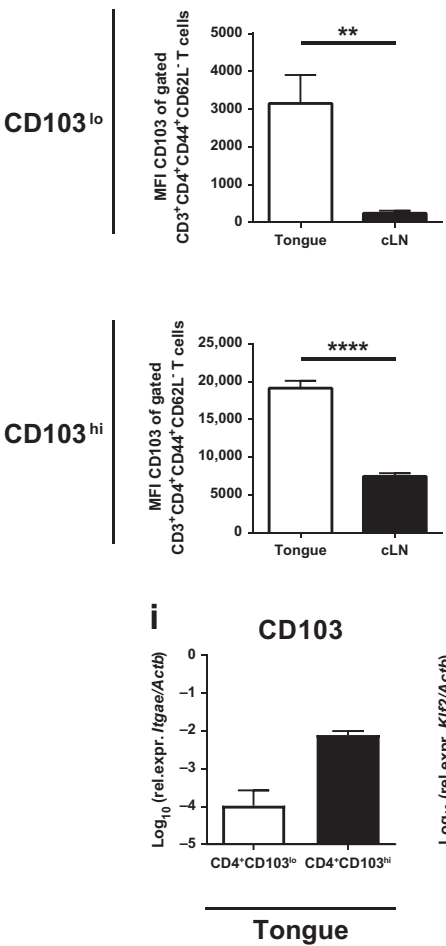
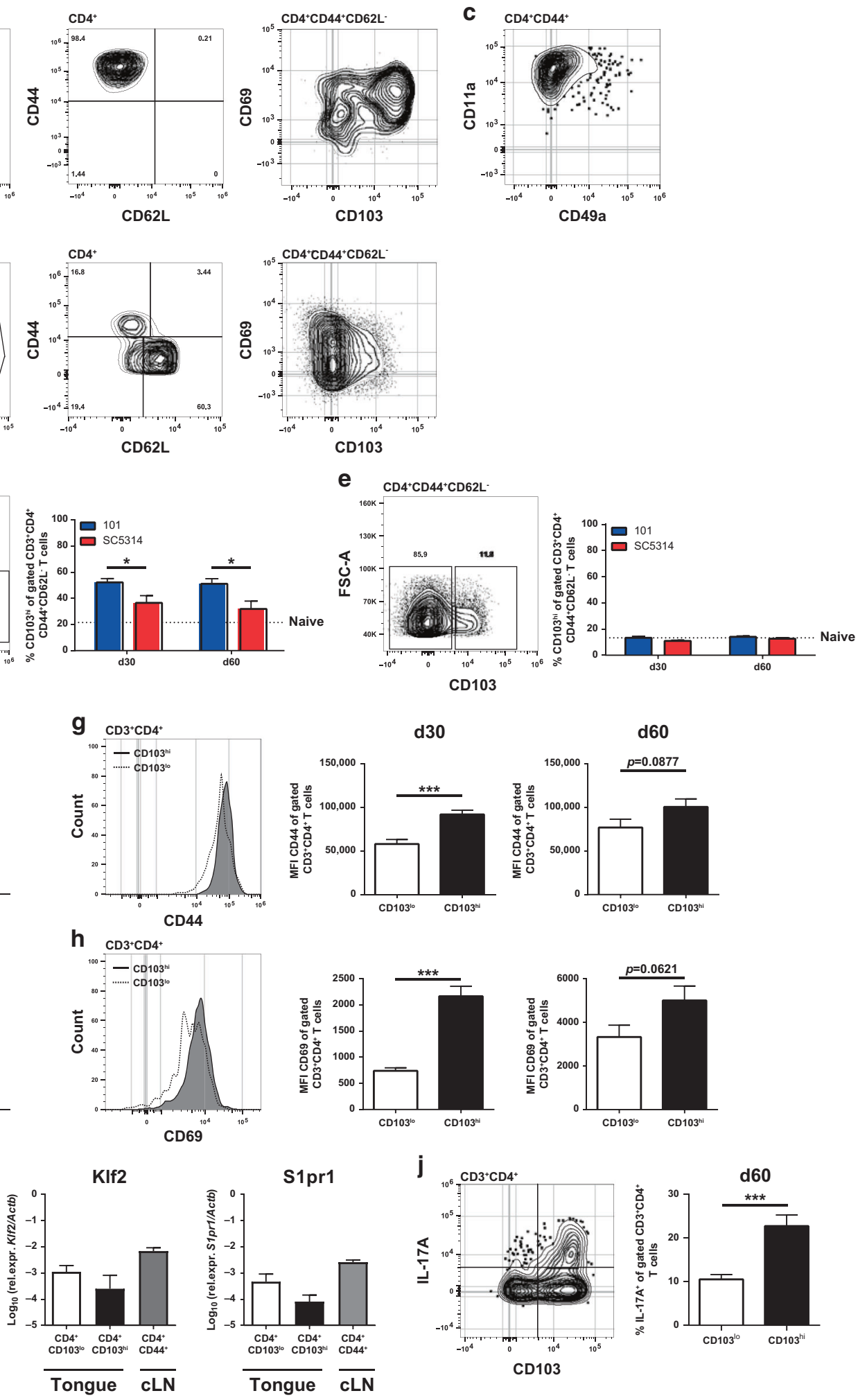

proportion of all $\mathrm{CD}^{+}{ }^{+} \mathrm{T}$ cells within the polyclonal $\mathrm{T}$ cell repertoire in the lymph nodes.

In the tongue of stably colonized mice, CD103 expression divided the $\mathrm{CD}^{+} \mathrm{T}_{\mathrm{RM}}$ cells into two subsets (Fig. $3 \mathrm{~d}$ ). The $\mathrm{CD} 103^{\text {hi }}$ and $C D 103^{\text {lo }} T_{R M}$ cell populations displayed higher expression levels of CD103 than their respective counterparts in the cervical lymph nodes (Fig. 3f). The average expression levels of CD44 and
CD69 of tongue $T_{R M}$ cells correlated with CD103 expression levels, i.e., the mean fluorescence intensity of both markers was higher in the $\mathrm{CD}_{103}{ }^{\text {hi }}$ compartment than in the $\mathrm{CD} 103^{\text {lo }}$ compartment at any time point analyzed (Fig. 3g, h). Moreover, KIf2 and S1pr1 transcripts were expressed at lower levels by the $C D 103^{\text {hi }}$ subset of $\mathrm{T}_{\mathrm{RM}}$ cells than in the CD103 $3^{\text {lo }}$ subset and by $\mathrm{CD} 44^{+}$lymph node $\mathrm{T}$ cells (Fig. 3i), consistent with a role of Klf2 in controlling the 
460

Fig. 3 Tongue CD4 $^{+} \mathbf{T}$ cells share phenotypic characteristics with $\mathbf{T}_{\mathrm{RM}}$ cells. WT mice were infected sublingually with C. albicans strain 101 (blue) or strain SC5314 (red) for the indicated time points. a-c CD3 ${ }^{+} \mathrm{CD} 4^{+} \mathrm{T}$ cells from the tongue $(\mathbf{a}, \mathbf{c})$ and the cervical lymph nodes (cLN, b) were analyzed by flow cytometry for CD44, CD62L, CD69, CD103, CD11a, and CD49a expression. Representative FACS plots show the situation in strain 101-infected mice on day 60 post infection. d, e CD44 ${ }^{+} \mathrm{CD} 62 \mathrm{~L}^{-} \mathrm{CD}^{+} \mathrm{CD}^{+} \mathrm{T}$ cells in the tongue (d) and the cervical lymph nodes (cLN, e) were divided into $\mathrm{CD} 103^{\mathrm{hi}}$ and $\mathrm{CD} 103^{\text {lo }}$ subsets. Representative FACS plots (left) show the situation in strain 101 -infected mice on day 60 post infection. Summary graphs (right) represent the mean + SEM of 6-13 individual mice per group pooled from 3-4 independent experiments. The dotted line represents the mean value determined in naive mice. $f$ The mean fluorescence intensity (MFI) of the

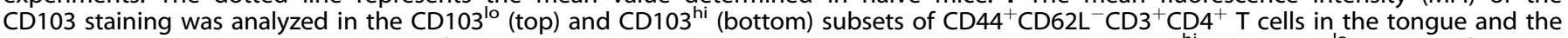
cervical lymph nodes (cLN). The MFI of the CD44 (g) and CD69 staining (h) was analyzed in the CD103 ${ }^{\text {hi }}$ and CD103 ${ }^{\text {lo }}$ subsets of tongue $\mathrm{CD}^{+} \mathrm{CD}^{+}{ }^{+}$cells. Representative FACS plots (left) show the situation on day 60 post infection. Summary graphs (middle and right) represent the mean + SEM of 7-13 individual mice per group pooled from $2-3$ independent experiments. $\mathbf{i}$ Tongue $C D 4^{+} C D 103^{\text {hi }}$ and $C D 4^{+} C D 103^{\text {lo }}$ T cell subsets and cervical lymph node (CLN) CD4 ${ }^{+} \mathrm{CD} 44^{+} \mathrm{T}$ cells were sorted from strain 101-infected animals on day 60-90 post infection and KIf2 and S1pr1 transcripts were quantified by RT qPCR. Itgae transcripts (coding for CD103) were quantified in the tongue $\mathrm{T}_{\mathrm{RM}}$ subsets as a control. Each bar represents the mean + SEM of 2-3 samples that were obtained by pooling the tongues or cervical lymph nodes from five mice each. j IL-17 production by tongue $\mathrm{CD} 4^{+} \mathrm{CD} 103^{\mathrm{hi}}$ and $\mathrm{CD} 4^{+} \mathrm{CD} 103^{\mathrm{lo}} \mathrm{T}$ cell subsets was analyzed by flow cytometry on day 60 post infection and after ex vivo re-stimulation with PMA and ionomycin for $4 \mathrm{~h}$ in the presence of Brefeldin A. A representative FACS plot is shown on the left; quantification of the frequency of $\mathrm{IL}-17^{+} \mathrm{CD} 3^{+} \mathrm{CD} 4^{+} \mathrm{T}$ cells in the tongue is shown on the right. Each bar represents the mean + SEM of five individual mice per group pooled from two independent experiments. Statistics were calculated using two-way ANOVA (d, e) or $t$-test $(\mathbf{f}-\mathbf{h}, \mathbf{j}),{ }^{*} p<0.05,{ }^{* *} p<0.01,{ }^{* * *} p<0.001,{ }^{* * *} p<0.0001$. See also Supplementary Figs. S3 and S4.

expression of $\mathrm{S} 1 \mathrm{pr} 1$, which is required for tissue egress. ${ }^{57}$ Finally, $\mathrm{CD}_{103}{ }^{\text {hi }} \mathrm{T}_{\mathrm{RM}}$ cells were the predominant source of IL-17 in the stably colonized tongue (Fig. 3j). Together, these results indicate that the accumulation and stable maintenance of $\mathrm{T}_{\mathrm{RM}}$ cells at the site of fungal colonization is a hallmark of the IL-17-mediated immunosurveillance response to the commensal fungus.

$T_{R M}$ cells in the tongue of stably colonized mice differ from $\mathrm{TCR}^{+} \mathrm{T}$ cells, which contribute to the IL-17 response at the onset of acute OPC with strain SC5314, ${ }^{41,42}$ as the latter express lower levels of CD103, CD44, and CD11a at the cell surface as well as higher levels of KIf2 and S1pr1 transcripts (Supplementary Fig. S4).

$\mathrm{CD}^{+} \mathrm{T}$ cells are located within the tongue parenchyma in stably colonized mice

To verify whether tongue $\mathrm{CD}^{+}{ }^{+} \mathrm{T}$ cells in stably colonized mice resided indeed within the tongue tissue and not in the vasculature, we selectively labeled T cells in the vasculature but not those within tissues by intravenous administration of a fluorochrome-conjugated anti-CD4 antibody five minutes prior to euthanasia. Blood and tongue T cells were stained ex vivo with a different clone of anti-CD4 to identify all $\mathrm{CD}^{+}{ }^{+} \mathrm{T}$ cells, irrespective of whether they had access to the in vivo administered antibody or not, and analyzed them by flow cytometry. While all $\mathrm{CD}^{+}$ $T$ cells in the blood were stained with both antibody clones, the $\mathrm{CD}^{+} \mathrm{T}$ cells in the tongue were protected from the injected antibody, indicating that they were indeed localized within the tissue and had not been in contact with the circulation (Fig. 4a, b).

To provide further evidence for the tissue residency of the CD4 $T$ cells in the tongue of stably colonized mice, we administered a CD4-specific depleting antibody. To check the depletion efficiency, remaining $\mathrm{CD}^{+} \mathrm{T}$ cells were stained ex vivo with a noncompeting antibody clone specific for CD4. ${ }^{58} 7$ days after systemic administration of the antibody, the frequency of $\mathrm{CD}^{+}{ }^{+}$cells was strongly diminished in the blood and in the cervical lymph nodes (Fig. $4 \mathrm{c}, \mathrm{d}$ ), while $\mathrm{CD}^{+} \mathrm{T}$ cell frequencies were comparatively increased in comparison to mice treated with an isotype control antibody (Supplementary Fig. S5). In contrast, in the tongue, the number of $\mathrm{CD}^{+} \mathrm{T}$ cells remained nearly unchanged in CD4depeleted animals compared to the isotype control group (Fig. 4e), although the median fluorescence intensity of the CD4 staining was somewhat reduced in depleting antibody-treated compared to isotype control-treated mice (Fig. 4f). These findings suggested that the anti-CD4 antibody or cells mediating depletion of antibody-bound cells did not access the $\mathrm{CD}^{+}{ }^{+} \mathrm{T}$ cells in the tongue parenchyma, even after the prolonged presence of the antibody in the circulation. This further indicated that during persistent colonization with $\mathrm{C}$. albicans, $\mathrm{CD}^{+}{ }^{+} \mathrm{T}$ cells are indeed tissue-resident and stably maintained in the tongue tissue independently of circulating $\mathrm{CD}^{+}{ }^{+} \mathrm{T}$ cells. Interestingly, within the tongue $\mathrm{CD}^{+}{ }^{+} \mathrm{T}$ cell compartment, we observed a shift in the ratio of $C D 103^{\text {hi }} / \mathrm{CD}_{103^{\mathrm{lo}} \mathrm{T}}$ cells with a relative increase in the CD103 ${ }^{\text {hi }}$ subset in the anti-CD4-treated group (Fig. 4g). This might suggest that the marginal depletion of $\mathrm{CD}^{+}{ }^{+} \mathrm{T}$ cells that was still observed, affected preferentially the $\mathrm{CD} 103^{\text {lo }}$ subset, which might be slightly more mobile in the epithelial tissue compared to their CD103 ${ }^{\text {hi }}$ counterpart.

Tongue $\mathrm{CD}^{+} \mathrm{T}$ cells in C. albicans-colonized mice are maintained independently of circulating $T$ cells

$T_{R M}$ cells exhibit little or no potential to recirculate and are maintained largely independently of the circulating T cell pool. ${ }^{59}$ To examine, whether this held also true for the $\mathrm{CD} 4^{+} \mathrm{T}$ cells in the tongue of mice that are stably colonized with C. albicans, we employed FTY720 (Fingolimod), a S1pr1 antagonist, to block the egress of lymphocytes from secondary lymphoid organs, thereby preventing lymphocyte recirculation. ${ }^{54}$ Administration of FTY720 to stably colonized mice for 3 weeks resulted in a strong decrease in the frequency and total numbers of circulating $\mathrm{CD} 4^{+} \mathrm{T}$ cells in comparison to untreated controls (Fig. 5a). The same was also true for $\mathrm{CD}^{+} \mathrm{T}$ cells (Supplementary Fig. S6A). In contrast, in the tongue, $\mathrm{CD}^{+}$and $\mathrm{CD}^{+} \mathrm{T}$ cell frequencies and absolute numbers remained stable (Fig. 5b, Supplementary Fig. S6B). Within the $\mathrm{CD}^{+} \mathrm{T}$ cell population, the distribution of the $\mathrm{CD}_{103}{ }^{\mathrm{hi}}$ and CD103 ${ }^{\text {lo }}$ subsets remained unchanged upon treatment with FTY720 (Fig. 5c). Finally, also their capacity to produce IL-17 was unaffected by the administration of FTY720 (Fig. 5d). Together, these data indicate that $\mathrm{CD}^{+}{ }^{+} \mathrm{T}$ cells are maintained in the $\mathrm{C}$. albicans-colonized mucosal tissue independently of the circulation, and thereby meet another key criterion for $\mathrm{T}_{\mathrm{RM}}$ cells.

$\mathrm{T}_{\mathrm{RM}}$ cells are sufficient to prevent overgrowth of commensal $C$. albicans in the oral mucosa

Finally, we sought to determine whether $T_{R M}$ cells in the $C$. albicans-colonized tongue were sufficient for maintaining commensalism and preventing fungal overgrowth. To this aim, we analyzed the fungal burden in the tongue of stably colonized mice that were treated for 3 weeks with FTY720, as described above (see Fig. 5), to prevent the supply of circulating T cells from the lymph nodes to the peripheral tissue. Indeed, FTY720-treatement did not affect $C$. albicans colonization loads (Fig. 6a), supporting the notion that $\mathrm{T}_{\mathrm{RM}}$ cells mediate antifungal control independently of the circulatory $\mathrm{T}$ cell compartment.

Moreover, we assessed the fungal burden in C. albicanscolonized mice, in which all circulating $\mathrm{CD}^{+}{ }^{+} \mathrm{T}$ cells, but not their tissue-resident counterparts, were depleted by means of an antiCD4 antibody (see Fig. 4c-f). Importantly, the colonization load in 
a

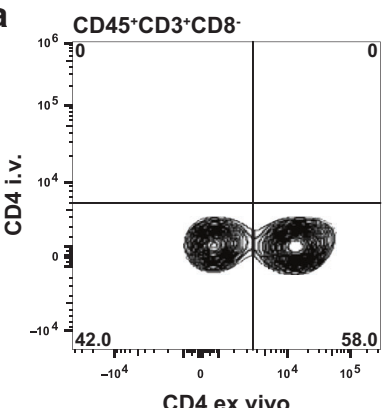

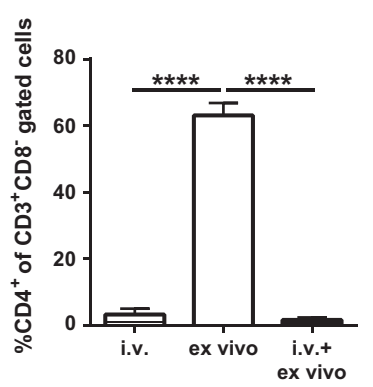

Tongue

C

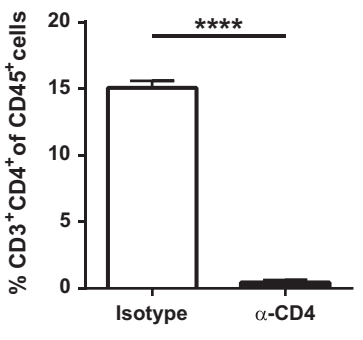

Blood

f

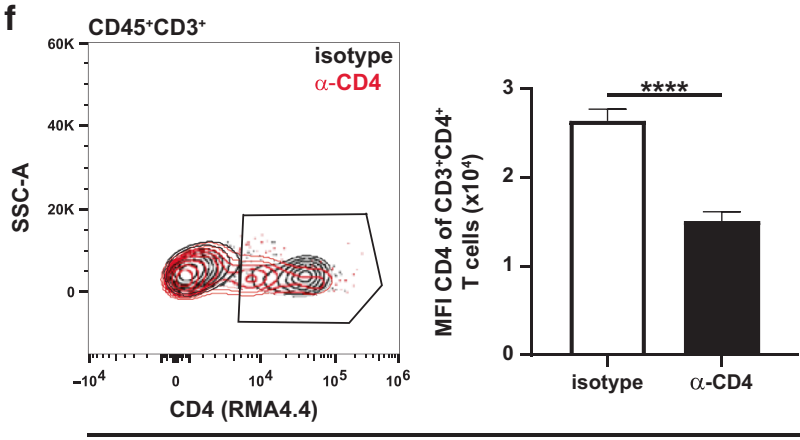

Tongue b

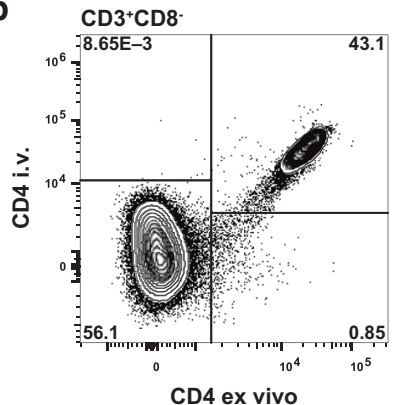

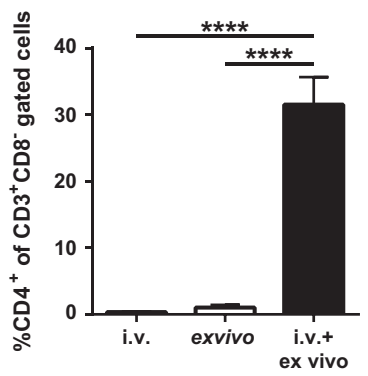

Blood

e

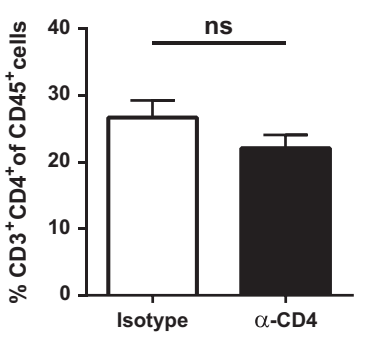

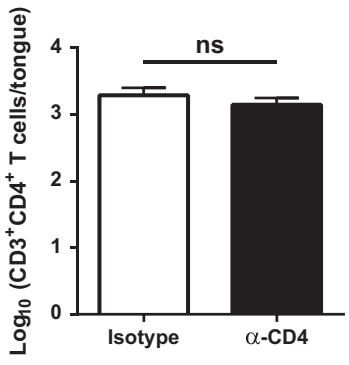

Tongue

g
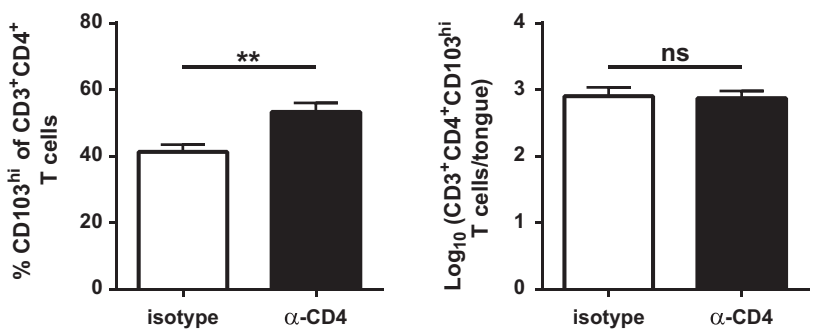

Tongue

Fig. $4 \mathrm{CD4}^{+} \mathrm{T}_{\mathrm{RM}}$ cells are located within the tongue tissue and not in the vasculature. WT mice were infected sublingually with $C$. albicans strain 101. a, b Forty-two days post infection, mice were injected intravenously with fluorescently labeled anti-CD4 antibody (clone RMA4.4) 5 min prior to sacrifice. Tongue (a) and blood (b) $\mathrm{CD}^{+} \mathrm{CD}^{-} \mathrm{T}$ cells were stained ex vivo with anti-CD4 (clone RMA4.5, conjugated to a different fluorochrome than the intravenously injected antibody). Representative FACS plots (left) and summary graphs (right) represent the percentages of intravenously labeled (i.v.), ex vivo stained and double-stained CD4 ${ }^{+} \mathrm{T}$ cells. c-g Twenty-one days post infection, mice were injected intraperitoneally with an anti-CD4 depleting antibody (clone GK1.5) or an isotype control for two consecutive days. Seven days later, the frequency of $\mathrm{CD}^{+}{ }^{+} \mathrm{CD} 4^{+} \mathrm{T}$ cells among $\mathrm{CD} 45^{+}$cells in the blood $(\mathbf{c})$, cervical lymph nodes (cLN, d) and tongue (e) was determined after ex vivo staining with a non-competing anti-CD4 antibody (clone RMA4.4). In the tongue, the analysis was complemented with the absolute numbers of $\mathrm{CD}^{+}{ }^{+} \mathrm{CD} 4^{+} \mathrm{T}$ cells $(\mathbf{e})$ and numbers and percentage of $\mathrm{CD} 103^{\text {hi }}$ cells among $\mathrm{CD} 3^{+} \mathrm{CD} 4^{+} \mathrm{T}$ cells $(\mathbf{g})$. The median fluorescence intensity (MFI) of the CD4 (clone RMA4.4) staining on tongue CD45 ${ }^{+} \mathrm{CD}^{+} \mathrm{T}$ cells is shown in (f) with representative FACS plots (left) and a summary graph (right). Data are the mean + SEM of 7-10 mice per group pooled from two independent experiments. Statistics were calculated using one-way ANOVA $(\mathbf{a}, \mathbf{b})$ or $t$-test $(\mathbf{c}-\mathbf{g}){ }^{* *} p<0.01,{ }^{* * * *} p<0.0001$. See also Supplementary Fig. S5.

the tongue was not significantly affected by the depletion of $\mathrm{CD}^{+}{ }^{\mathrm{T}}$ cells in the blood and cervical lymph nodes (Fig. 6b), indicating that the $C$. albicans-specific $\mathrm{CD} 4^{+} \mathrm{T}$ cells retained in the tongue after anti-CD4 administration were sufficient to keep fungal growth in check, independently of the circulating antifungal $\mathrm{CD}^{+} \mathrm{T}$ cell pool. The situation in both of these settings was thus markedly distinct from what we observed in $\mathrm{Rag}^{-1-}$ and TCRbd ${ }^{-1-}$ mice that are completely devoid of T cells, where fungal growth was out of control (see Supplementary Fig. S1). Together, these results provide evidence that bona fide $\mathrm{T}_{\mathrm{RM}}$ cells in the $C$. albicans-colonized mucosa provide local surveillance of fungal commensalism.
$T_{R M}$ cells level out fluctuations in the $C$. albicans colonization load We hypothesized that the maintenance of a high frequency of $C$. albicans-specific $T_{R M}$ cells in stably colonized mice might confer an advantage by creating a state of alert that ensures a rapid response to fluctuations in the fungal load as they naturally occur. ${ }^{60,61}$ To simulate such oscillations in the fungal load in our experimental model, we chose to superinfect stably colonized mice with an additional inoculum of $C$. albicans (Supplementary Fig. S7A). Within 4 days after superinfection, we observed a significant increase in IL17-secreting $T_{R M}$ cells in the tongue compared to stably colonized mice that were not superinfected (Supplementary Fig. S7B-D). Of note, the enhanced Th17 response observed during the 

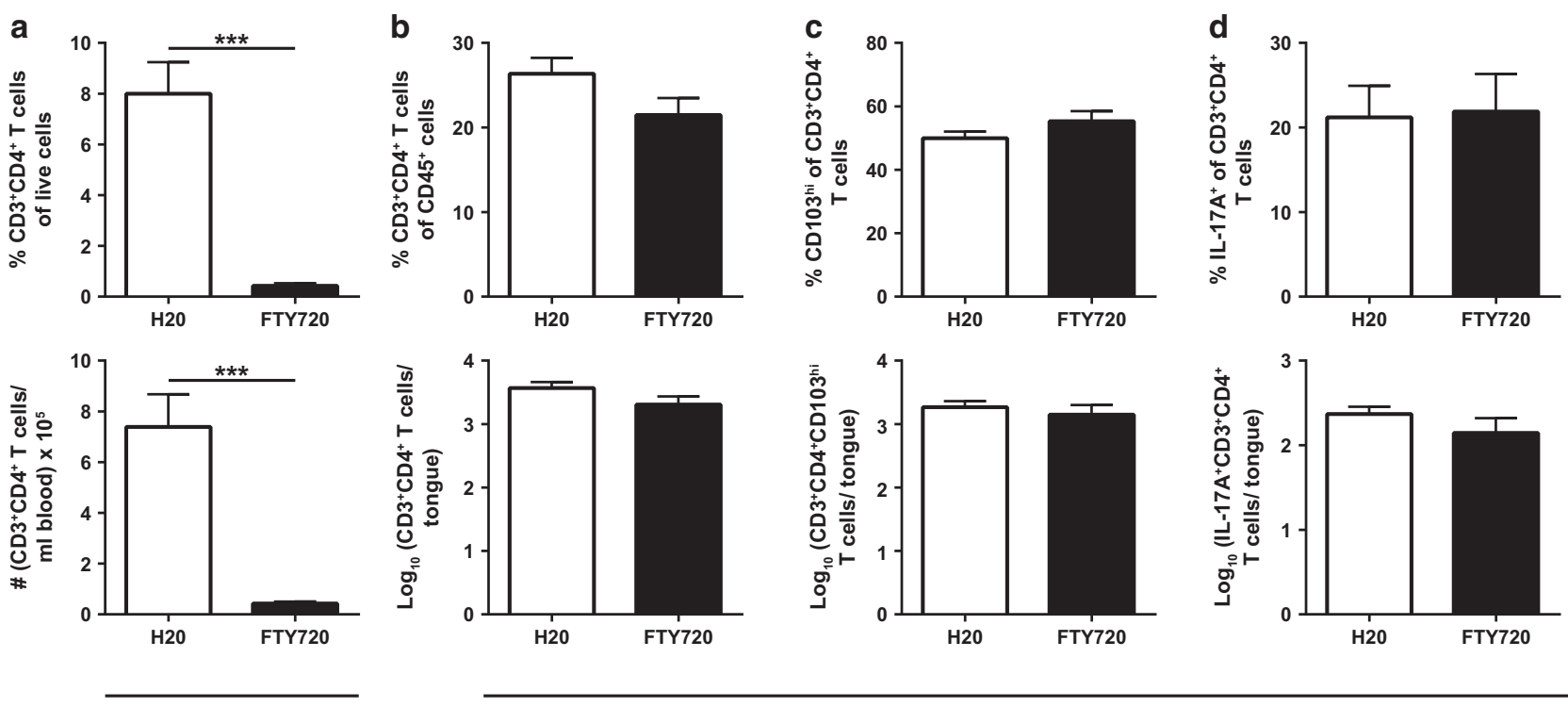

Blood

Tongue

Fig. $5 \mathrm{CD4}^{+} \mathrm{T}$ cells are maintained in the tongue of $C$. albicans-colonized mice independently of circulating $\mathrm{T}$ cells. WT mice were infected sublingually with C. albicans strain 101. 21 days post infection, FTY720 was administered in the drinking water for 3 weeks and CD ${ }^{+}$CD4 ${ }^{+}$ $\mathrm{T}$ cells in the blood and in the tongue were analyzed by flow cytometry. Frequencies (top) and absolute numbers (bottom) of $\mathrm{CD} 3^{+} \mathrm{CD} 4^{+}$ T cells in the blood (a) and in the tongue (b), respectively. c Frequency (top) and absolute numbers (bottom) of $\mathrm{CD} 103^{\text {hi }} \mathrm{CD} 3^{+} \mathrm{CD} 4^{+} \mathrm{T}$ cells in the tongue. d Frequency (top) and absolute numbers (bottom) of IL-1 $7^{+} \mathrm{CD} 3^{+} \mathrm{CD} 4^{+} \mathrm{T}$ cells in the tongue. Cytokine production was analyzed after re-stimulation with PMA and ionomycin for $4 \mathrm{~h}$ in the presence of Brefeldin A. Data are the mean + SEM of ten mice per group pooled from two independent experiments. Statistics were calculated using $t$-test, ${ }^{* * *} p<0.001$. See also Supplementary Fig. S6.
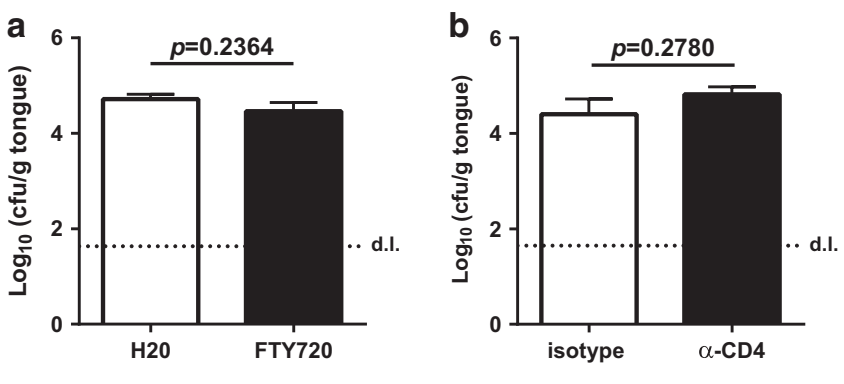

\section{Tongue}

Fig. $6 T_{\mathrm{RM}}$ cells are sufficient for preventing overgrowth of commensal C. albicans in the oral mucosa. a WT mice were infected and treated with FTY720 as in Fig. 5. Plots show tongue cfu on day 42 post infection. b WT mice were infected and treated with depleting anti-CD4 antibody as in Fig. 4c-f. Plots show tongue cfu on day 7 after T cell depletion. Each bar represents the mean + SEM of 7-10 mice per group pooled from two independent experiments. Statistics were calculated using $t$-test. The dotted line represents the detection limit (d.I.). See also Supplementary Fig. S7.

superinfection correlated with improved fungal control (Supplementary Fig. S7E). The tongue fungal load in superinfected mice was lower than that of non-primed mice, which were infected for just 4 days and even lower than in persistently colonized animals that were not superinfected (Supplementary Fig. S7E). Together, these results emphasize the relevance of $T_{R M}$ cells in the colonized tissue to level fluctuations in colonization load and to retain homeostatic levels of commensal C. albicans.

Tongue $T_{R M}$ cells provide enhanced fungal control after cleared infection and secondary fungal exposure

The function of $T_{R M}$ cells has been studied before in various infection models with organisms that are readily cleared in mice, including a model of epicutaneous candidiasis with strain SC5314 where $T_{R M}$ cells were found to significantly improve pathogen control during re-infection with the same organism. ${ }^{62}$ In Fig. 3, we observed that a small population of tongue $T_{\mathrm{RM}}$ cells was also induced during transient OPC. Therefore, we questioned whether $T_{R M}$ cells contribute to or possibly even suffice for fungal control during recurrent candidiasis in the oral mucosa as during persistent colonization. We employed the model of transient OPC with strain 101 as in Fig. 2c, in which we eliminated the fungus on day 8 after the primary infection by administration of fluconazole (Fig. 7a). As expected, transient exposure of mice to $C$. albicans resulted also in the generation of circulatory $\mathrm{T}$ cell memory as evidenced by an enhanced Th17 response in the cervical lymph nodes upon re-infection (Supplementary Fig. S8A) and an increased proliferation of $\mathrm{T}_{\mathrm{EM}}$ cells (Supplementary Fig. S8B, C). We speculated that these circulatory memory $T$ cells possibly contribute to local fungal control in the oral mucosa during re-infection. Therefore, to uncouple the involvement of $T_{R M}$ cells in the tongue from circulatory memory T cells, we made use of FTY720 treatment. FTY720 was administered to mice that had or had not been transiently exposed to C. albicans strain 101 to induce circulatory lymphopenia (Fig. 7a). Importantly, while pre-existing antifungal memory conferred enhanced fungal control, FTY720 treatment had no impact on the tongue fungal load in primed mice (Fig. 7b), indicating that $T_{R M}$ cells in the tongue were sufficient for optimal fungal control and circulatory memory $T$ cells were not required. Consistent with this, we observed a stark increase in the number of tongue $\mathrm{CD}^{+} \mathrm{T}$ cells upon re-infection (Fig. 7d), most of which expressed high levels of CD103 (Fig. 7e), and this was largely independent of FTY720. In contrast, blood CD4 ${ }^{+}$ T cells were markedly decreased upon FTY720 treatment (Fig. 7c), as expected. Collectively, both in transiently infected and in stably colonized mice, a population of $\mathrm{T}_{\mathrm{RM}}$ cells persists locally in the tongue and efficiently controls the fungus to either prevent overgrowth during recurrent infection or to control persistent fungus during commensalism, respectively. 


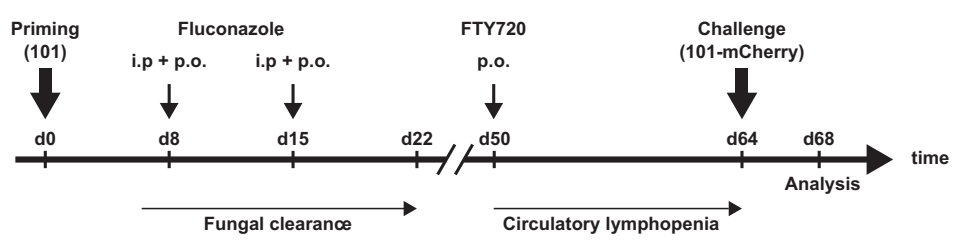

C
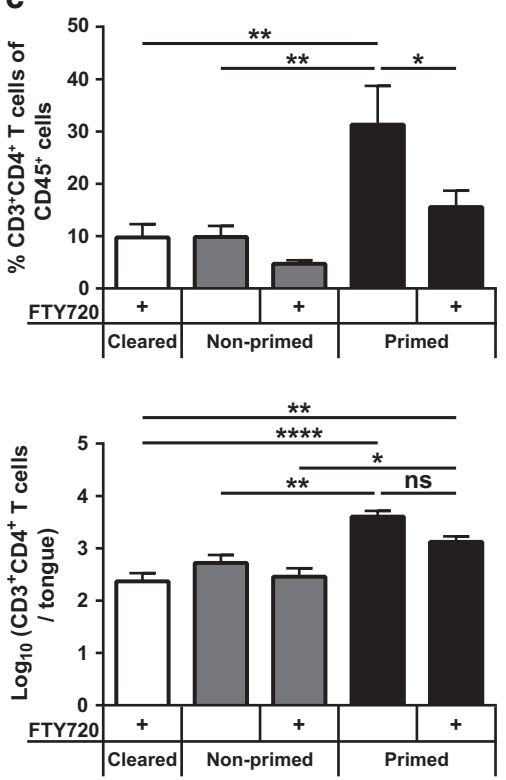

d
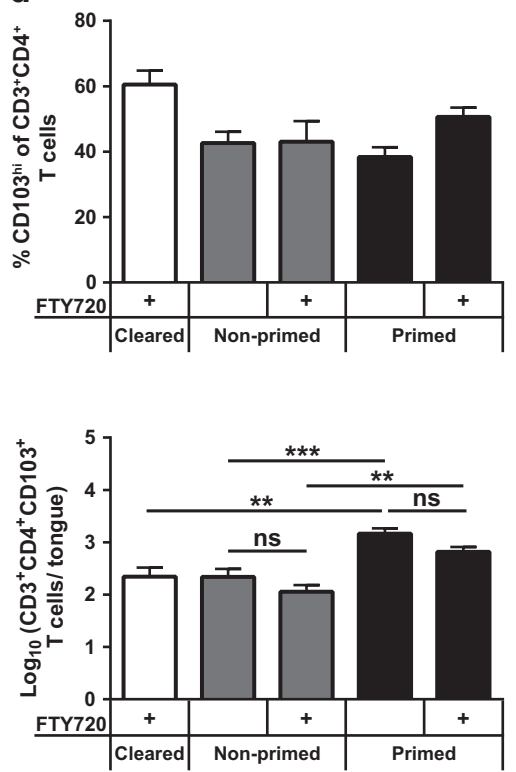

b
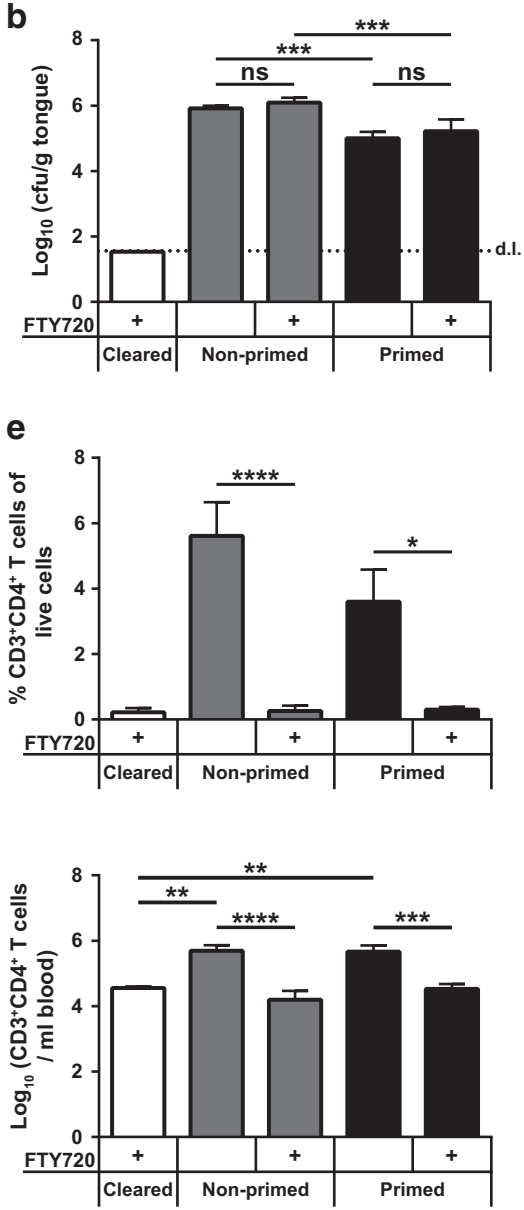

Blood

Fig. 7 Tongue $T_{R M}$ cells also provide protection against transient infection during secondary exposure. WT mice were infected sublingually with C. albicans strain 101 and treated with fluconazole for 2 weeks starting from day 8 post infection. Starting from day 42 post infection, mice were or were not treated with FT720, as indicated, and were re-infected 14 days later with strain 101-mCherry for 4 days. As a control, a group of naive mice was included that did not receive the first infection with strain 101 (non-primed). Moreover, a group of mice was included, which was transiently infected with strain 101 and then treated with fluconazole but did not receive the second infection with strain 101-mCherry (cleared), as indicated. Four days after re-infection, fungal burden and T cells were analyzed in the tongue. a Schematic outline of the experiment. b Tongue cfu on day 4 post infection in the indicated groups. The dotted line represents the detection limit (d.I.). The frequencies (top) and absolute numbers (bottom) of $\mathrm{CD}^{+} \mathrm{CD}^{+} \mathrm{T}$ cells in the tongue (c) and in the blood $(\mathbf{e})$ and of $\mathrm{CD} 103^{\text {hi }} \mathrm{CD} 3^{+} \mathrm{CD} 4^{+}$ $T$ cells in the tongue (d) were analyzed by flow cytometry. Each bar represents the mean + SEM of 6-8 mice per group pooled from two independent experiments. Statistics were calculated using or one-way ANOVA, ${ }^{*} p<0.05,{ }^{* *} p<0.01,{ }^{* * *} p<0.001,{ }^{* * * *} p<0.0001$. See also Supplementary Fig. S8.

\section{DISCUSSION}

Fungi are increasingly recognized as integral part of the microbiota. Their interaction with the host can have manifold consequences, as exemplified by $C$. albicans, which confers hostbeneficial properties but at the same time bears a risk for the host through its potential to cause infection and/or to promote immunopathology. ${ }^{3}$ Tight control by the immune system is essential to prevent dysbiosis. IL-17-mediated immunity and especially Th17 cells are indispensable for the control of $C$. albicans in mucosal barrier tissues. However, the Th17 response to C. albicans during homeostasis remains poorly characterized. In the past, most mechanistic studies on antifungal $T$ cell immunity employed models of acute and transient infection in mice. In this study, we made use of a novel experimental model of persistent oral colonization and found that $C$. albicans-induced $T$ cells in the stably colonized tongue exhibit phenotypic and functional properties of $T_{R M}$ cells, including high expression of CD103, CD69, and CD11a, low expression of KIf2 and S1pr1, localization within the tissue and maintenance independently of the circulation. Importantly, we found that these $\mathrm{T}_{\mathrm{RM}}$ cells are responsible for mediating immunosurveillance of the fungus and to maintain stable commensalism.

Antigen-specific Th17 cells are efficiently primed in response to C. albicans, irrespective of the strain virulence. ${ }^{45} \mathrm{~T}$ cell activation and differentiation in experimentally infected mice is comparable between the low-virulent strain 101 and the highly virulent strain SC5314, although immediate innate immunity and the degree of inflammation induced at the site of infection differ greatly between the two strains. ${ }^{45}$ Differences in the Th17 response become apparent only later during infection. While the C. albicansspecific $T$ cell pool rapidly contracts after resolution of acute OPC, Th17 cells are stably maintained at high numbers in the oral mucosa during persistent colonization. Reminiscent of what was recently reported in a model of intestinal colonization with $C$. albicans, ${ }^{18}$ the maintenance of a large $C$. albicans-specific $T$ cell population depends on the continuous presence of the fungus. 
464

The same was also observed in various models of bacterial and parasitic infections. ${ }^{63-65}$ The fact that fungus-specific T cells are only maintained at high numbers if they are needed, may represent a means to prevent immunopathology, as $C$. albicansspecific T cells can also bear a pathogenic potential. ${ }^{18,19}$

The Th17 response is stably maintained in colonized mice without IFN- $\gamma$ - or GM-CSF-producing T cells appearing over time. This is consistent with the absence of inflammation in colonized mice, even under conditions of reduced immune regulation, such as regulatory $\mathrm{T}$ cells or IL-10 deficiency. ${ }^{48}$ In contrast, dysregulation of the Th17 response results in uncontrolled fungal growth. Together, our new model of $C$. albicans colonization closely mimics the situation of $C$. albicans commensalism in humans and therefore represents a suitable model for studying the immune mechanisms that regulate homeostasis at the fungus-host interface. Importantly and in contrast to other currently available models of fungal colonization in mice, such as the model of gastrointestinal colonization, ${ }^{66}$ our model does not depend on the pretreatment of mice with antibiotics or immunosuppressants. Furthermore, our model recapitulates the situation in humans regarding the quality of the Th17 response. C. albicans-specific Th17 cells can be readily detected in the blood of all individuals that have been exposed to the fungus during the course of their life. These human circulating $T$ cells have a memory phenotype, ${ }^{67,68}$ consistent with the $T_{E M}$ cells that we observed in the lymph nodes of stably colonized mice. In contrast, $C$. albicans-specific memory $T$ cells in the mucosa, where $C$. albicans effectively resides, belong to the $T_{R M}$ cell subset. $T_{R M}$ cells that react to $C$. albicans have also been identified in the normal skin of healthy individuals. ${ }^{62}$

$T_{R M}$ cells are strategically located in epithelial barrier tissues such as the skin, the lung, and the gastrointestinal and female reproductive tract. Phenotypically, they are characterized by the constitutive expression of the tissue retention markers CD69 and CD103. ${ }^{54,59,69}$ The majority of all studies on $T_{\text {RM }}$ cells to date have focused on $\mathrm{CD}^{+} \mathrm{T}_{\mathrm{RM}}$ cells, but $\mathrm{CD}^{+} \mathrm{T}_{\mathrm{RM}}$ cells share the key hallmarks of this specialized subset of memory T cells. ${ }^{70}$ Our study is the first to report on $\mathrm{CD}^{+} \mathrm{T}_{\mathrm{RM}}$ cells in the oral mucosa. Tongue $\mathrm{CD}^{+} \mathrm{T}_{\mathrm{RM}}$ cells share all the phenotypic and functional characteristics that have been established for $\mathrm{T}_{\mathrm{RM}}$ cells in other tissues.

Functionally, $\mathrm{T}_{\mathrm{RM}}$ cells are poised for rapid local effector function, independently of the circulating pool of $T$ cells. Their functional relevance has been studied in infection models with various pathogens that are swiftly cleared from the murine host. Evidence for a protective role of $T_{R M}$ cells in these models was established under settings of re-call infections. ${ }^{54}$ These examples include a model of acute $C$. albicans skin infection with strain SC5314. ${ }^{62}$ We confirmed these published data in our study using a setting of transient OPC. A host-protective role of $T_{R M}$ cells has also been evidenced in the context of chronic infections with pathogenic viruses, such as HSV and CMV. ${ }^{71}$ In human tissues, $\mathrm{CD}^{+}$or $\mathrm{CD}^{+} \mathrm{T}_{\mathrm{RM}}$ cells have been identified, including those specific to CMV, RSV, Epstein-Barr virus, HSV, HBV, HIV, and IAV ${ }^{54}$ and correlations have been made between increased populations of virus-specific $T_{R M}$ cells and enhanced viral control. ${ }^{72-75}$ Moreover, growing evidence points toward a role for $T_{R M}$ cells in inflammatory disorders and autoimmunity, both in humans and mice. $^{69}$

Keeping in check the myriads of (normally harmless) microbes to which we are constantly exposed is probably the most profound challenge for the immune system. The lack of tight control of the microbiota results in microbial overgrowth at the epithelial barriers and microbial invasion of internal organs, which are usually sterile. Therefore, effective immune mechanisms are required to ensure a peaceful cohabitation with commensal organisms, on which we strongly depend for important physiological functions. Homeostatic immunity is a highly complex process that involves cellular and humoral components of the immune system. Our study adds $T_{R M}$ cells as a central component of effective long-term surveillance of commensal organisms, as exemplified by persistent $C$. albicans colonization in the oral mucosa. Based on our results, we postulate that regulating homeostasis of the microbiota may represent the most fundamental role of $T_{R M}$ cells in addition to all other scenarios, in which they have been implicated. Although our study is limited to C. albicans, a common and well documented inhabitant of the oro-gastrointestinal and female reproductive tract, $\mathrm{T}_{\mathrm{RM}}$ cells are likely implicated more generally in the control of other fungal and bacterial commensals.

\section{MATERIALS AND METHODS}

\section{Reagents}

All reagents, antibodies, mouse and fungal strains, instruments, and software used in this study are listed in Supplementary Table S1. Further information and requests for resources and reagents should be directed to and will be fulfilled by the lead contact S.L.L. The DC ${ }^{1940}$ cell line (University of Lausanne) was obtained via an MTA between the University of Zürich and the respective entity.

\section{Ethic statement}

All mouse experiments in this study were conducted in strict accordance with the guidelines of the Swiss Animals Protection Law and were performed under the protocols approved by the Veterinary office of the Canton of Zürich, Switzerland (license number 201/2012, 183/2015 and 166/2018). All efforts were made to minimize suffering and ensure the highest ethical and humane standards according to the $3 \mathrm{R}$ principles.

Animals

WT C57BL/6j mice were purchased by Janvier Elevage. Rag $1^{-1-, 76}$ TCRbd $^{-1-, 77,78} / 117 a f^{-1-, 79} \mathrm{Tg}\left(\right.$ TcraTcrb)603Biat (Hector) ${ }_{1}^{49} / 123 \mathrm{r}^{\text {GFP/GFP }}$ mice ${ }^{80}$ as well as congenic CD45.1 $1^{+}$and CD45. $1^{+}$CD 45.2 $2^{+}$WT mice were bred and maintained at the Institute of Laboratory Animals Science (LASC), University of Zürich. All mice were on the C57BL/6 background. The animals were kept in specific pathogen-free conditions and used at 6-15 weeks of age in sex- and age-matched groups. Infected and uninfected animals were kept separately to avoid cross-contamination. Female as well as male mice were used for experiments.

\section{Fungal strains}

C. albicans strains SC5314 ${ }^{81}$ and $101^{45}$ were grown in YPD medium at $30^{\circ} \mathrm{C}$ and $180 \mathrm{rpm}$ for $15-18 \mathrm{~h}$. 101-mCherry was generated by transformation of strain 101 with a plasmid pADH-Cherry-SAT1 ${ }^{82}$ digested with $B a m H I$, which introduces the plasmid into the $A D H I$ locus. Transformation was performed as described by a lithium acetate method. ${ }^{83}$ Selection of transformants was carried out on nourseothricin-containing YPD plates $(200 \mu \mathrm{g} / \mathrm{ml})$.

Murine OPC model

Mice were infected sublingually with $2.5 \times 10^{6} \mathrm{C}$. albicans yeast cells as described, ${ }^{84}$ without immunosuppression. In some experiments, mice were treated with Fluconazole $(400 \mu \mathrm{g} / \mathrm{mouse}$ i.p. on day 7-8 post infection followed by administration of $0.2 \mathrm{mg} / \mathrm{ml}$ Fluconazole in the drinking water). Fungal clearance was checked 7 days after the initial treatment by plating fecal material on YPD plates. Secondary infections (re-infection or superinfection) were done $\sim 60$ days after the primary infection using C. albicans strain 101-mCherry to discriminate the fungus from the primary and secondary infection.

Determination of the fungal burden

For determination of the fungal burden, the tongue of euthanized animals was removed, homogenized in sterile 0.05\% NP40 in $\mathrm{H}_{2} \mathrm{O}$ 
for $3 \mathrm{~min}$ at $25 \mathrm{~Hz}$ using a Tissue Lyzer (Qiagen) and serial dilutions were plated on YPD agar containing $100 \mu \mathrm{g} / \mathrm{ml}$ Ampicillin.

\section{Histology}

For histology, tissue was fixed in 4\% PBS-buffered paraformaldehyde overnight and embedded in paraffin. Sagittal sections $(9 \mu \mathrm{m})$ were stained with Periodic-acidic Schiff reagent and counterstained with Haematoxilin and mounted with Pertex (Biosystem) according to standard protocols. Images were acquired with a digital slide scanner (NanoZoomer 2.0-HT, Hamamatsu) and analyzed with NDP.view2.

\section{$\mathrm{CD}^{+} \mathrm{T}$ cell depletion}

Mice were injected intraperitoneally with $500 \mu \mathrm{g}$ of anti-CD4 antibody (clone GK1.5, BioXCell) or rat IgG2b isotype control (BioXCell) on day 21 and again on day 22 post infection. Mice were analyzed 7 days after antibody administration. anti-CD4 (clonse RMA4.4) was used to monitor the efficiency of T cell depletion by flow cytometry.

\section{FTY720 treatment}

Mice were treated with $5 \mu \mathrm{g} / \mathrm{ml}$ FTY720 (Selleckchem) in the drinking water. The depletion efficiency was monitored by quantification of $\mathrm{CD}^{+}{ }^{+} \mathrm{T}$ cells in the blood on the day of analysis.

Isolation of lymph node cells and ex vivo T cell re-stimulation Cervical lymph nodes were removed, and single cell suspensions were prepared by digestion with DNase I $(2.4 \mathrm{mg} / \mathrm{ml}$, Roche) and Collagenase I ( $2.4 \mathrm{mg} / \mathrm{ml}$, Invitrogen) in PBS for $15 \mathrm{~min}$ at $37^{\circ} \mathrm{C}$. For inducing cytokine production by primed T cells, $10^{6}$ cervical lymph node cells were re-stimulated for $6 \mathrm{~h}$ with $1 \times 10^{5} \mathrm{DC}^{1940}$ cells $^{85}$ that were pulsed with $2.5 \times 10^{5} / \mathrm{ml}$ heat-killed $C$. albicans. Unpulsed $D^{1940}$ cells served as negative control. Brefeldin A $(10 \mu \mathrm{g} / \mathrm{ml}$, AppliChem) was added for the last $5 \mathrm{~h}$ to inhibit the secretory pathway.

Isolation of tongue cells and ex vivo $T$ cell re-stimulation Mice were perfused by injection of PBS into the right heart ventricle prior to removing the tongue. Tongues were cut in half and the underlying muscle tissue was carefully removed using a scalpel. The remaining tongue tissue was cut into small pieces and digested with DNase I $(2.4 \mathrm{mg} / \mathrm{ml})$ and Collagenase IV $(2.4 \mathrm{mg} / \mathrm{ml})$ in PBS for $45 \mathrm{~min}$ at $37^{\circ} \mathrm{C}$. Single cell suspensions were obtained by passing the digested tissue through a $70 \mu \mathrm{m}$ strainer using ice cold PBS supplemented with 1\% FCS and 2 mM EDTA and then stained for flow cytometry. For inducing cytokine production by tongue $T$ cells, cells were stimulated with phorbol 12-myristate 13acetate (PMA, $50 \mathrm{ng} / \mathrm{ml}$, Sigma-Aldrich) and lonomycin $(500 \mathrm{ng} / \mathrm{ml}$, Sigma-Aldrich) for $4 \mathrm{~h}$ in the presence of Brefeldin A $(10 \mu \mathrm{g} / \mathrm{ml})$ at $37^{\circ} \mathrm{C}$.

\section{Flow cytometry}

Single cell suspensions of tongue and lymph nodes were stained in PBS supplemented with $1 \% \mathrm{FSC}, 5 \mathrm{mM}$ EDTA and $0.02 \% \mathrm{NaN}_{3}$. LIVE/DEAD Near IR stain (Life Technologies) was used for exclusion of dead cells. The antibodies for surface and intracellular cytokine staining are listed in Supplementary Table S1. For intracellular cytokine staining, cells were fixed and permeabilized using BD Cytofix/Cytoperm reagent (BD Bioscience) and subsequently incubated in Perm/Wash buffer (BD Bioscience). All extracellular and intracellular staining steps were carried out on ice. For intranuclear Ki-67 staining, cells were fixed and permeabilized for 40 min at RT using the Foxp3 Staining Buffer Set (eBioscience) and subsequently stained for $40 \mathrm{~min}$ at RT in Permeabilization buffer (eBioscience). Cells were acquired on a FACS Gallios (Beckman Coulter) or a SP6800 Spectral Analyzer (Sony). Data were analyzed with FlowJo software (FlowJo LLC). The gating of the flow cytometric data was performed according to the guidelines for the use of flow cytometry and cell sorting in immunological studies, ${ }^{86}$ including pre-gating on viable and single cells for analysis. Absolute cell numbers of lymphocyte populations were calculated based on a defined number of counting beads (BD Bioscience, Calibrite Beads), which were added to the samples before flow cytometric acquisition.

\section{FACS sorting, RNA isolation and RT qPCR}

For sorting cells from the tongue and cervical lymph nodes, single cell suspensions were stained in PBS, supplemented with $1 \%$ FSC and 5 mM EDTA, with a viability marker and antibodies directed against CD45, TCR- $\beta, C D 3, C D 4, C D 44$, and CD103. Using a FACS Aria III (BD Biosciences), 400-2500 target cells per defined population were sorted per well of a 96-well plate (Eppendorf) containing RLT Plus RNeasy ${ }^{\oplus}$ lysis buffer (Qiagen). Lysates were snap-frozen and stored at $-80^{\circ} \mathrm{C}$ until further processing. Wholetranscriptome amplification was performed following the SmartSeq2 protocol $^{87}$ and according to ref. ${ }^{41}$. RT-qPCR was performed using SYBR Green (Roche) and a QuantStudio 7 Flex (Life Technology) instrument. The primers are listed in Supplementary Table $S 1^{34,57,88}$. All RT-qPCR assays were performed in duplicates and the relative expression (rel. expr.) of each gene was determined after normalization to Actb transcript levels.

\section{Intravascular CD4 staining}

Mice were injected intravenously with $5 \mu \mathrm{g}$ of FITC- or BV605conjugated anti-CD4 antibody (clone RMA4.4) in $200 \mu$ l of PBS 5 min prior to euthanasia. Blood was collected prior to perfusion of the mice and removal of the tongue. Ex vivo staining of T cells was carried out using anti-CD4 antibody (clone RMA4.5).

Adoptive transfer of C. albicans-primed polyclonal $\mathrm{CD}^{+}{ }^{+} \mathrm{T}$ cells WT mice were infected sublingually for 8 days with $C$. albicans strain 101. Cervical lymph nodes were processed as described above and $\mathrm{CD}^{+}{ }^{+} \mathrm{T}$ cells were enriched to high purity using antiCD4 microbeads following the manufacturer's instructions (Miltenyi Biotec). A total of $10^{6} \mathrm{CD}^{+} \mathrm{T}$ cells were injected intravenously into $\operatorname{Rag} 1^{-1-}$ mice, which were infected sublingually with $C$. albicans strain 101 on the following day.

Adoptive transfer of $C$. albicans-specific Hector $\mathrm{CD}^{+}{ }^{+} \mathrm{T}$ cells $\mathrm{CD}^{+} \mathrm{T}$ cells were first enriched from spleens of naive TCRtransgenic Hector mice ${ }^{49}$ with anti-CD4 microbeads (Miltenyi Biotec) following the manufacturer's instructions and then stained with a viability marker and antibodies directed against CD3, CD4, CD90, CD44, and TCRVa2 and sorted on a FACS Aria II Cell Sorter (BD Biosciences). A total of $10^{6} \mathrm{CD}^{+} \mathrm{TCRVa2}^{+} \mathrm{CD} 44^{-}$Hector CD4 ${ }^{+}$ $\mathrm{T}$ cells were injected intravenously into $\operatorname{Rag} 1^{-1-}$ mice 1 day prior to sublingual infection with C. albicans strain 101. Hector T cells were identified by gating on $\mathrm{CD}^{+} \mathrm{CD}^{+}{ }^{+} \mathrm{CD} 90.1^{+} \mathrm{TCRVa}^{+}$cells.

\section{Chimeras}

For generation of mixed bone marrow chimeras, CD45. $1^{+} \mathrm{CD} 45.2^{+}$ WT recipient mice were irradiated twice with a dose of $5.5 \mathrm{~Gy}$ at an interval of $12 \mathrm{~h}$. Next, bone marrow from CD45.1 $1^{+} \mathrm{WT}$ and CD45.2 $2^{+} 1123 r^{G F P / G F P}$ donor mice was collected, washed twice with PBS under sterile conditions, mixed at a 1:1 ratio and injected intravenously into irradiated recipient mice $18 \mathrm{~h}$ after the second irradiation. Mice were treated with Borgal ${ }^{\oplus}$ (MSD Animal Health $\mathrm{GmbH}$ ) p.o. for the first 2 weeks of a total of a 8 week reconstitution period.

\section{Quantification and statistical analysis}

Statistical significance was determined by unpaired Student's $t$ test with Welch's correction or one- or two-way ANOVA with the Dunnet's or Tukey's multiple comparison test, as appropriate, using GraphPad Prism software. Data displayed on a logarithmic scale were log-transformed before statistical 
analysis. Outlier calculation was performed using the ROUT method. Significance is indicated as follows: ${ }^{*} p<0.05$; ${ }^{* *} p<0.01$; ${ }^{* * *} p<0.001 ;{ }^{* * * *} p<0.0001$.

\section{DATA AVAILABILITY}

All raw data and metadata linked to this study are available on Zenodo (https://doi. org/10.5281/zenodo.3933969).

\section{ACKNOWLEDGEMENTS}

The authors would like to thank Dominique Sanglard for generating 101-mCherry; Nicole Joller for help with RNA isolation and CDNA amplification; the staff of the Laboratory Animal Service Center of University of Zürich for animal husbandry; staff of the Laboratory for Animal Model Pathology of University of Zürich for histology; members of the LeibundGut-lab for helpful advice and discussions. This work was supported by the Swiss National Science Foundation (grant \#310030_166206), the University of Zürich Research Talent Development Fund, and The Foundation for Research in Science and the Humanities at the University of Zürich (grant \#STW-17-017). Open Access funding provided by Universität of Zürich.

\section{AUTHOR CONTRIBUTIONS}

Conceptualization: F.R.K. and S.L.L.; Methodology: F.R.K.; Investigation: F.R.K..; Formal analysis: F.R.K.; Validation: S.L.L.; Visualization: F.R.K. and S.L.L.; Project administration: S.L.L.; Funding acquisition: S.L.L.; Supervision: S.L.L.; Writing: F.R.K. and S.L.L.

\section{ADDITIONAL INFORMATION}

The online version of this article (https://doi.org/10.1038/s41385-020-0327-1) contains supplementary material, which is available to authorized users.

Competing interests: The authors declare no competing interests.

Publisher's note Springer Nature remains neutral with regard to jurisdictional claims in published maps and institutional affiliations.

\section{REFERENCES}

1. Underhill, D. M. \& Iliev, I. D. The mycobiota: interactions between commensal fungi and the host immune system. Nat. Rev. Immunol. 14, 405-416 (2014).

2. Iliev, I. D. \& Leonardi, I. Fungal dysbiosis: immunity and interactions at mucosal barriers. Nat. Rev. Immunol. 17, 635-646 (2017).

3. Limon, J. J., Skalski, J. H. \& Underhill, D. M. Commensal fungi in health and disease. Cell Host Microbe 22, 156-165 (2017).

4. Brown, G. D. et al. Hidden killers: human fungal infections. Sci. Transl. Med. 4, 165rv13 (2012).

5. Ghannoum, M. A. et al. Characterization of the oral fungal microbiome (mycobiome) in healthy individuals. PLoS Pathog. 6, e1000713 (2010).

6. Dupuy, A. K. et al. Redefining the human oral mycobiome with improved practices in amplicon-based taxonomy: discovery of Malassezia as a prominent commensal. PloS ONE 9, e90899 (2014).

7. lliev, I. D. et al. Interactions between commensal fungi and the C-type lectin receptor Dectin-1 influence colitis. Science 336, 1314-1317 (2012).

8. Hoffmann, $C$. et al. Archaea and fungi of the human gut microbiome: correlations with diet and bacterial residents. PLOS ONE 8, e66019 (2013).

9. Drell, T. et al. Characterization of the vaginal micro- and mycobiome in asymptomatic reproductive-age Estonian women. PLoS ONE 8, e54379 (2013).

10. Findley, K. et al. Topographic diversity of fungal and bacterial communities in human skin. Nature 498, 367-370 (2013).

11. Revankar, S. G. \& Sobel, J. D. Candida and Candidiasis, 2nd ed. (American Society of Microbiology, 2012).

12. Pappas, P. G., Lionakis, M. S., Arendrup, M. C., Ostrosky-Zeichner, L. \& Kullberg, B. J. Invasive candidiasis. Nat. Rev. Dis. Prim. 4, 18026 (2018).

13. Richard, M. L., Lamas, B., Liguori, G., Hoffmann, T. W. \& Sokol, H. Gut fungal microbiota: the Yin and Yang of inflammatory bowel disease. Inflamm. Bowel Dis. 21, 656-665 (2015).

14. Li, X. V., Leonardi, I. \& Iliev, I. D. Gut mycobiota in immunity and inflammatory disease. Immunity 50, 1365-1379 (2019).

15. Iliev, I. D. et al. Interactions between commensal fungi and the C-type lectin receptor Dectin-1 influence colitis. Science 336, 1314-1317 (2012).

16. Limon, J. J. et al. Malassezia is associated with Crohn's disease and exacerbates colitis in mouse models. Cell Host Microbe 25, e6 (2019).
17. Jostins, L. et al. Host-microbe interactions have shaped the genetic architecture of inflammatory bowel disease. Nature 491, 119-124 (2012)

18. Shao, T.-Y. et al. Commensal Candida albicans positively calibrates systemic Th17 immunological responses. Cell Host Microbe 25, e6 (2019).

19. Bacher, P. et al. Human anti-fungal Th17 immunity and pathology rely on crossreactivity against Candida albicans. Cell 176, e15 (2019).

20. Lanternier, F. et al. Primary immunodeficiencies underlying fungal infections. Curr. Opin. Pediatrics 25, 736-747 (2013).

21. Anwar, K. P., Malik, A. \& Subhan, K. H. Profile of candidiasis in HIV infected patients. Iran. J. Microbiol. 4, 204-209 (2012).

22. Liu, L. et al. Gain-of-function human STAT1 mutations impair IL-17 immunity and underlie chronic mucocutaneous candidiasis. The. J. Exp. Med. 208, 1635-1648 (2011).

23. van de Veerdonk, F. L. et al. STAT1 mutations in autosomal dominant chronic mucocutaneous candidiasis. N. Engl. J. Med. 365, 54-61 (2011).

24. Okada, S. et al. Impairment of immunity to Candida and Mycobacterium in humans with bi-allelic RORC mutations. Science 349, 606-613 (2015).

25. Glocker, E.-O. et al. A homozygous CARD9 mutation in a family with susceptibility to fungal infections. N. Engl. J. Med. 361, 1727-1735 (2009).

26. Drewniak, A. et al. Invasive fungal infection and impaired neutrophil killing in human CARD9 deficiency. Blood. 121, 2385-2392 (2013).

27. Beaucoudrey, Lde et al. Mutations in STAT3 and IL12RB1 impair the development of human IL-17-producing T cells. J. Exp. Med. 205, 1543-1550 (2008).

28. Ma, C. S. et al. Deficiency of Th17 cells in hyper lgE syndrome due to mutations in STAT3. J. Exp. Med. 205, 1551-1557 (2008).

29. Milner, J. D. et al. Impaired $\mathrm{T}(\mathrm{H}) 17$ cell differentiation in subjects with autosomal dominant hyper-lgE syndrome. Nature 452, 773-776 (2008).

30. Renner, E. D. et al. Novel signal transducer and activator of transcription 3 (STAT3) mutations, reduced $\mathrm{T}(\mathrm{H}) 17$ cell numbers, and variably defective STAT3 phosphorylation in hyper-lgE syndrome. J. Allergy Clin. Immunol. 122, 181-187 (2008).

31. Puel, A. et al. Chronic mucocutaneous candidiasis in humans with inborn errors of interleukin-17 immunity. Science 332, 65-68 (2011).

32. Boisson, B. et al. An ACT1 mutation selectively abolishes interleukin-17 responses in humans with chronic mucocutaneous candidiasis. Immunity 39, 676-686 (2013).

33. Ling, Y. et al. Inherited IL-17RC deficiency in patients with chronic mucocutaneous candidiasis. The. J. Exp. Med. 212, 619-631 (2015).

34. Gladiator, A., Wangler, N., Trautwein-Weidner, K. \& LeibundGut-Landmann, S. Cutting edge: IL-17-secreting innate lymphoid cells are essential for host defense against fungal infection. J. Immunol. 190, 521-525 (2013).

35. Trautwein-Weidner, K., Gladiator, A., Nur, S., Diethelm, P. \& LeibundGut-Landmann, S. IL-17-mediated antifungal defense in the oral mucosa is independent of neutrophils. Mucosal Immunol. 8, 221-231 (2015).

36. Conti, H. R. et al. IL-17 receptor signaling in oral epithelial cells is critical for protection against Oropharyngeal Candidiasis. Cell Host Microbe 20, 606-617 (2016).

37. Conti, H. R. et al. Th17 cells and IL-17 receptor signaling are essential for mucosal host defense against oral candidiasis. J. Exp. Med. 206, 299-311 (2009).

38. Kagami, S., Rizzo, H. L., Kurtz, S. E., Miller, L. S. \& Blauvelt, A. IL-23 and IL-17A, but not IL-12 and IL-22, are required for optimal skin host defense against Candida albicans. J. Immunol. 185, 5453-5462 (2010).

39. Ho, A. W. et al. IL-17RC is required for immune signaling via an extended SEF/IL17R signaling domain in the cytoplasmic tail. J. Immunol. 185, 1063-1070 (2010).

40. Kashem, S. W. et al. Nociceptive sensory fibers drive interleukin-23 production from $\mathrm{CD} 301 \mathrm{~b}+$ dermal dendritic cells and drive protective cutaneous immunity. Immunity 43, 515-526 (2015).

41. Sparber, F. et al. Langerin + DCs regulate innate IL-17 production in the oral mucosa during Candida albicans-mediated infection. PLoS Pathog. 14, e1007069 (2018).

42. Conti, H. R. et al. Oral-resident natural Th17 cells and $\gamma \delta T$ cells control opportunistic Candida albicans infections. J. Exp. Med. 211, 2075-2084 (2014).

43. Ropars, J. et al. Gene flow contributes to diversification of the major fungal pathogen Candida albicans. Nat. Commun. 9, 2253 (2018).

44. Hirakawa, M. P. et al. Genetic and phenotypic intra-species variation in Candida albicans. Genome Res. 25, 413-425 (2015).

45. Schönherr, F. A. et al. The intraspecies diversity of $C$. albicans triggers qualitatively and temporally distinct host responses that determine the balance between commensalism and pathogenicity. Mucosal Immunol. 10, 1335-1350 (2017).

46. MacCallum, D. M. et al. Property differences among the four major Candida albicans strain clades. Eukaryot. Cell 8, 373-387 (2009).

47. Moyes, D. L. et al. Candidalysin is a fungal peptide toxin critical for mucosal infection. Nature 532, 64-68 (2016).

48. Kirchner, F. R. et al. Persistence of Candida albicans in the oral mucosa induces a curbed inflammatory host response that is independent of immunosuppression. Front. Immunol. 10, 330 (2019).

49. Trautwein-Weidner, K. et al. Antigen-specific Th17 cells are primed by distinct and complementary dendritic cell subsets in oropharyngeal candidiasis. PLoS Pathog. 11, e1005164 (2015) 
50. Bar, E. et al. A novel Th cell epitope of Candida albicans mediates protection from fungal infection. J. Immunol. 188, 5636-5643 (2012).

51. Hernandez-Santos, N. et al. Th17 cells confer long-term adaptive immunity to oral mucosal Candida albicans infections. Mucosal Immunol. 6, 900-910 (2013).

52. Sparber, F. \& LeibundGut-Landmann, S. Assessment of immune responses to fungal infections: identification and characterization of immune cells in the infected tissue. Methods Mol. Biol. 1508, 167-182 (2017).

53. Gaffen, S. L., Jain, R., Garg, A. V. \& Cua, D. J. The IL-23-IL-17 immune axis: from mechanisms to therapeutic testing. Nat. Rev. Immunol. 14, 585-600 (2014).

54. Szabo, P. A., Miron, M. \& Farber, D. L. Location, location, location: tissue resident memory $T$ cells in mice and humans. Sci. immunol. 4; https://doi.org/10.1126/ sciimmunol.aas9673 (2019).

55. Mackay, L. K. et al. Cutting edge: CD69 interference with sphingosine-1phosphate receptor function regulates peripheral T cell retention. J. Immunol. 194, 2059-2063 (2015)

56. Cepek, K. L. et al. Adhesion between epithelial cells and T lymphocytes mediated by E-cadherin and the alpha E beta 7 integrin. Nature 372, 190-193 (1994).

57. Skon, C. N. et al. Transcriptional downregulation of S1pr1 is required for the establishment of resident memory CD8+ T cells. Nat. Immunol. 14, 1285-1293 (2013).

58. Laky, K. \& Kruisbeek, A. M. In vivo depletion of T lymphocytes. Curr. Protoc. Immunol. 113, 4.1.1-4.1.9 (2016).

59. Mueller, S. N. \& Mackay, L. K. Tissue-resident memory T cells: local specialists in immune defence. Nat. Rev. Immunol. 16, 79-89 (2016).

60. Auchtung, T. A. et al. Investigating colonization of the healthy adult gastrointestinal tract by fungi. mSphere 3, e00092-18 (2018).

61. Zollner-Schwetz, I. et al. Oral and intestinal Candida colonization in patients undergoing hematopoietic stem-cell transplantation. J. Infect. Dis. 198, 150-153 (2008).

62. Park, C. O. et al. Staged development of long-lived T-cell receptor alphabeta TH17 resident memory T-cell population to Candida albicans after skin infection. J. Allergy Clin. Immunol. 142, 647-662 (2018).

63. Schulz, S. M., Kohler, G., Holscher, C., Iwakura, Y. \& Alber, G. IL-17A is produced by Th17, gammadelta $T$ cells and other CD4- lymphocytes during infection with Salmonella enterica serovar Enteritidis and has a mild effect in bacterial clearance. Int. Immunol. 20, 1129-1138 (2008).

64. Khader, S. A. et al. IL-23 compensates for the absence of IL-12p70 and Is Essential for the $\mathrm{IL}-17$ response during tuberculosis but is dispensable for protection and antigen-specific IFN- $\gamma$ responses if IL-12p70 is available. J. Immunol. 175, 788 (2005).

65. Pedraza-Zamora, C. P., Delgado-Dominguez, J., Zamora-Chimal, J. \& Becker, I. Th17 cells and neutrophils: Close collaborators in chronic Leishmania mexicana infections leading to disease severity. Parasite immunol. 39; https://doi.org/ 10.1111/pim.12420 (2017).

66. Koh, A. Y. Murine models of Candida gastrointestinal colonization and dissemination. Eukaryot. cell 12, 1416-1422 (2013).

67. Acosta-Rodriguez, E. V. et al. Surface phenotype and antigenic specificity of human interleukin 17-producing T helper memory cells. Nat. Immunol. 8, 639-646 (2007).

68. Bacher, P. et al. Human anti-fungal Th17 immunity and pathology rely on crossreactivity against Candida albicans. Cell 176, e15 (2019).

69. Masopust, D. \& Soerens, A. G. Tissue-resident T cells and other resident leukocytes. Annu. Rev. Immunol. 37, 521-546 (2019).

70. Nguyen, Q. P., Deng, T. Z., Witherden, D. A. \& Goldrath, A. W. Origins of CD4(+) circulating and tissue-resident memory T-cells. Immunology 157, 3-12 (2019).

71. Thom, J. T., Weber, T. C., Walton, S. M., Torti, N. \& Oxenius, A. The salivary gland acts as a sink for tissue-resident memory $\mathrm{CD} 8(+) \mathrm{T}$ cells, facilitating protection from local cytomegalovirus infection. Cell Rep. 13, 1125-1136 (2015).
72. Jozwik, A. et al. RSV-specific airway resident memory CD8+ T cells and differential disease severity after experimental human infection. Nat. Commun. 6, 10224 (2015).

73. Zhu, J. et al. Immune surveillance by CD8alphaalpha+ skin-resident $T$ cells in human herpes virus infection. Nature 497, 494-497 (2013).

74. Buggert, M. et al. Identification and characterization of HIV-specific resident memory CD8(+) T cells in human lymphoid tissue. Sci. immunol. 3; https://doi. org/10.1126/sciimmunol.aar4526 (2018).

75. Pallett, L. J. et al. IL-2(high) tissue-resident T cells in the human liver: sentinels for hepatotropic infection. J. Exp. Med. 214, 1567-1580 (2017).

76. Mombaerts, $P$. et al. RAG-1-deficient mice have no mature $B$ and T lymphocytes. Cell 68, 869-877 (1992).

77. Itohara, S. et al. T cell receptor delta gene mutant mice: independent generation of alpha beta T cells and programmed rearrangements of gamma delta TCR genes. Cell 72, 337-348 (1993).

78. Mombaerts, $\mathrm{P}$. et al. Mutations in T-cell antigen receptor genes alpha and beta block thymocyte development at different stages. Nature 360, 225-231 (1992).

79. Haas, J. D. et al. Development of interleukin-17-producing gammadelta $T$ cells is restricted to a functional embryonic wave. Immunity 37, 48-59 (2012).

80. Awasthi, A. et al. Cutting edge: IL-23 receptor gfp reporter mice reveal distinct populations of IL-17-producing cells. J. Immunol. 182, 5904-5908 (2009).

81. Odds, F. C., Brown, A. J. P. \& Gow, N. A. R. Candida albicans genome sequence: a platform for genomics in the absence of genetics. Genome Biol. 5, 230 (2004).

82. Keppler-Ross, S., Noffz, C. \& Dean, N. A new purple fluorescent color marker for genetic studies in Saccharomyces cerevisiae and Candida albicans. Genetics 179, 705 (2008).

83. Sanglard, D., Ischer, F., Monod, M. \& Bille, J. Susceptibilities of Candida albicans multidrug transporter mutants to various antifungal agents and other metabolic inhibitors. Antimicrobial Agents Chemother. 40, 2300-2305 (1996).

84. Solis, N. V. \& Filler, S. G. Mouse model of oropharyngeal candidiasis. Nat. Protoc. 7, 637-642 (2012).

85. Fuertes Marraco, S. A. et al. Novel murine dendritic cell lines: a powerful auxiliary tool for dendritic cell research. Front. Immunol. 3, 331 (2012).

86. Cossarizza, A. et al. Guidelines for the use of flow cytometry and cell sorting in immunological studies. Eur. J. Immunol. 49, 1457-1973 (2019).

87. Picelli, S. et al. Full-length RNA-seq from single cells using Smart-seq2. Nat. Protoc. 9, 171-181 (2014).

88. Bergsbaken, T., Bevan, M. J. \& Fink, P. J. Local inflammatory cues regulate differentiation and persistence of CD8+ tissue-resident memory T cells. Cell Rep. 19, 114-124 (2017).

(c) (i) Open Access This article is licensed under a Creative Commons Attribution 4.0 International License, which permits use, sharing, adaptation, distribution and reproduction in any medium or format, as long as you give appropriate credit to the original author(s) and the source, provide a link to the Creative Commons license, and indicate if changes were made. The images or other third party material in this article are included in the article's Creative Commons license, unless indicated otherwise in a credit line to the material. If material is not included in the article's Creative Commons license and your intended use is not permitted by statutory regulation or exceeds the permitted use, you will need to obtain permission directly from the copyright holder. To view a copy of this license, visit http://creativecommons. org/licenses/by/4.0/.

(c) The Author(s) 2020 